\title{
Sequential Delivery of a Novel Triple Drug Combination via Crosslinked Alginate/lactoferrin Nanohybrids for Enhanced Breast Cancer Treatment
}

\author{
Mai Salah \\ Alexandria University \\ Marwa A. Sallam \\ Alexandria University \\ Mona A. Abdelmoneem \\ Alexandria University \\ Mohamed Teleb \\ Alexandria University \\ Kadria A. Elkhodairy \\ Alexandria University \\ Adnan A. Bekhit \\ Alexandria University \\ Asmaa F. Khafaga \\ Alexandria University \\ Ahmed E. Noreldin \\ Damanhur University \\ Ahmed O. Elzoghby \\ Alexandria University \\ Sherine N. Khattab ( $\nabla$ sherinekhattab@alexu.edu.eg )
}

Alexandria University

\section{Research Article}

Keywords: Protein/polysaccharide nanohybrids, Sodium alginate, Lactoferrin, Rosuvastatin, Pemetrexed, Honokiol

Posted Date: February 7th, 2022

DOI: https://doi.org/10.21203/rs.3.rs-1316017/v1

License: () (i) This work is licensed under a Creative Commons Attribution 4.0 International License. Read Full License 


\section{Abstract}

While breast cancer remains a global health concern, the elaboration of rationally designed drug combinations coupled with advanced biocompatible delivery systems offers new promising treatment venues. Herein, we repurposed rosuvastatin (RST) based on its selective tumor apoptotic effect and combined it with the antimetabolite pemetrexed (PMT) and the tumorsensitizing polyphenol honokiol (HK). This synergistic three-drug combination was incorporated into protein polysaccharide nanohybrids fabricated utilizing sodium alginate (ALG) and lactoferrin (LF), inspired by the stealth property of the former and the cancer cell targeting capability of the latter. ALG was conjugated to PMT and then coupled with LF conjugated to RST, forming core shell nanohybrids into which HK was physically loaded followed by cross linking using genipin. The crosslinked HK-loaded PMT-ALG/LF-RST nanohybrids exhibited fair drug loading of 7.86, 5.24 and $6.11 \%$ for RST, PMT and HK, respectively. It demonstrated an 8-fold decrease in the $\mathrm{IC}_{50}$ compared to the free drug combination, in addition to showing enhanced cellular uptake by MCF-7 cells. The in vivo antitumor efficacy in a breast cancer-bearing mouse model confirmed the superiority of the triple cocktail-loaded nanohybrids, as demonstrated by suppression of tumor growth and inhibition of ki-67 and VEGF-1 expression in addition to upregulation of caspase-3 expression. Conclusively, our rationally designed triple drug-loaded protein/polysaccharide nanohybrids offer a promising, biocompatible approach for effective breast tumor suppression.

\section{Introduction}

Breast cancer is the second most common cause of death in women after lung cancer [1]. Many reports have suggested that by 2050, breast cancer will spread to reach approximately 3.2 million new cases [2]. Extensive efforts are continuously ongoing to develop new chemotherapeutics for clinical purposes. While traditional anticancer treatment remains a major clinical concern, new strategies are now being implemented to overcome the main restrictions of chemotherapy ranging from random biodistribution to systemic toxicity [3]. In that context, numerous nanoparticle (NP) based delivery systems have been developed to deliver single or combined anticancer agents. The use of a combination strategy represents a successful approach for chemotherapy treatment [4]. To overcome multidrug resistance (MDR) and enhance drug effectiveness against both drugresistant and drug-sensitive cancer cells by enhancing chemosensitivity and drug bioaccessibility, some nanodrug delivery systems have been developed by combining nanotechnology with multidrug chemosensitization [5]. Pemetrexed (PMT) is an active multidirectional antifolate cytotoxic chemotherapeutic drug against various kinds of cancer, such as breast cancer [6]. However, the clinical benefits are limited due to its poor therapeutic results related to the inability to achieve sufficient intracellular concentrations at the doses limit allowed, while increasing the PMT dose results in systemic toxicity and MDR. PMT also has low bioavailability and selectivity [7].

Accordingly, several attempts have been made to enhance the antitumor effect of PMT, such as combining it with other chemotherapeutic agents or phytomedicines $[8,9]$. In addition, the bioavailability of PMT has been improved, and side effects have been reduced by various targeted drug delivery systems through the coupling of drugs with enhancer peptides or nanoformulations [10].

Rosuvastatin (RST) is one of the statins used to treat hypercholesterolemia $[11,12]$. It mediates its action by suppressing $\beta$ hydroxy $\beta$-methylglutaryl-CoA (HMG-CO A) reductase and blocking the mevalonate (MVA) pathway. Suppression of the MVA pathway in addition to reducing cholesterol synthesis has been reported to induce selective tumor cell apoptosis events [13]. Unfortunately, when the MVA pathway is blocked by statins, a restorative feedback response is triggered and thus triggers the activation of the sterol regulatory element-binding protein 2 (SREBP2) to restore homeostasis. It has been reported that blocking SREBP2 processing using drugs such as honokiol (HK) enhances the ability of statins to activate apoptosis of cancer cells [14]. Additionally, RST induces the inhibition of the Ras-Raf-1-MAPK signaling pathway, which could synergize with the apoptotic action of PMT, enhancing its cytotoxicity [15].

Moreover, HK, which is an herbal extract of Magnolia grandiflora seeds, has attracted much attention by virtue of its advantageous antitumor actions. HK suppresses P-glycoprotein efflux pumps to make drug-resistant tumor cells sensitive to chemotherapeutic drugs [16], thereby enhancing the efficiency of PMT by minimizing the occurrence of MDR. Accordingly, the synergistic combination of PMT, RST and HK is expected to improve their antitumor efficacy in breast cancer therapy. 
The delivery of chemotherapeutics with nanosized polymeric carriers offers various advantages, including efficient drug loading, targeted release and enhanced accumulation of drug in tumor cells, which reduces the side effects in addition to enhanced circulation times and better bioavailability [17]. Among nanocarriers, protein- and polysaccharide-based NPs have many advantages, such as biodegradability, biocompatibility, ease of functionalization, negligeable toxicity profiles and enhanced biodistribution [18-20]. Natural proteins and polysaccharides can be utilized in chemical coupling because they have many reactive functional groups, including carboxylic, thiol and amino groups. Accordingly, we combined the advantages of protein polysaccharide nanohybrids and polymeric drug conjugates to elaborate an injectable platform for hydrophobic anticancer agents ensuring stability in the bloodstream and allowing release at the tumor site [21].

The NP shell requires stealth properties to prevent reticuloendothelial recognition and subsequent removal, thus allowing passive accumulation in tumor cells. Polysaccharides, such as sodium alginate (ALG), can provide stealth properties for nanoparticles and reduce plasma protein adsorption [22]. ALG is a hydrophilic salt of alginic acid that is a nontoxic, natural polysaccharide that exists in all types of brown algae. Additionally, ALG is a biodegradable polymer employed extensively in the medical, food and pharmaceutical industries. Previous studies have reported many applications of ALG for drug delivery, and it has been used to prepare sustained release delivery systems for various drugs [23].

Furthermore, lactoferrin (LF), a member of the transferrin family, has antioxidant, anti-inflammatory, immunostimulatory and established anticancer effects. Internalization of LF into cancer cells has been reported due to its great affinity to bind with many receptors overexpressed on the surface of tumor cells, such as LF receptors (LRP1, LRP2) and low-density lipoprotein (LDL). Moreover, the nuclear localization sequence of LF enables it to be internalized into the nucleus and the site of action of most chemotherapeutics, and it is reported to target the delivery of cytotoxic agents to tumor cells [24]. In our study, LF was utilized as a nanocarrier to improve the loading capacity, antitumor efficacy and solubility of the hydrophobic drug RST.

Herein, we propose crosslinked ALG/LF NHs to deliver PMT, RST and HK for breast cancer treatment. First, PMT, a highly soluble chemotherapeutic drug, has been conjugated to ALG to attenuate its release into the systemic circulation, therefore minimizing side effects and enhancing accumulation within tumor cells. Second, RST was conjugated to the LF polymer to provide a sustained release pattern of RST and increase its solubility. Third, protein-polysaccharide (PMT-ALG/LF-RST) NHs were developed by chemical coupling. Fourth, HK, which is a hydrophobic drug, has been incorporated into the hydrophobic core of nanohybrids to overcome its solubility problem. Finally, crosslinking of HK-loaded PMT-ALG/LF-RST NHs with genipin was performed to enhance the stability of its structure, sustain drug release and prohibit its premature disintegration. The developed nanohybrids demonstrated greater antitumor effects than the free drug combination using in vitro and in vivo investigations.

\section{Materials And Methods}

\subsection{Materials}

The supplementary file includes all the chemicals utilized in this research.

\subsection{Preparation of crosslinked HK-loaded PMT-ALG/LF-RST NHs F10}

\subsubsection{Preparation of alginate/lactoferrin nanohybrids (ALG/LF NHs) F1}

The nanohybrids were fabricated through a carbodiimide coupling reaction between the carboxyl groups of ALG and LF amino groups. Sodium alginate $(0.05 \mathrm{~g})$ was dissolved in $7 \mathrm{~mL}$ double filtrated distilled $\mathrm{H}_{2} \mathrm{O}$. The preactivation of the carboxylic acid groups of ALG was performed for $5 \mathrm{~min}$ by the in situ addition of $(0.01 \mathrm{~g}, 0.05 \mathrm{mmol}) \mathrm{EDC}$. $\mathrm{HCl}$ and $(0.009 \mathrm{~g}, 0.05 \mathrm{mmol}) \mathrm{K}$. Oxyma at room temperature (RT) for 5 min under constant stirring. An aqueous solution of $(0.10 \mathrm{~g}, 0.00125 \mathrm{mmol})$ lactoferrin (5 $\mathrm{mL}$ ) was added dropwise to the reaction mixture. The reaction mixture was stirred overnight. Dialysis was performed on the resulting solution against double filtrated distilled $\mathrm{H}_{2} \mathrm{O}$ for $48 \mathrm{~h}$ to eliminate the byproducts, and lyophilization of the product was performed for further investigation.

\subsubsection{Preparation of lactoferrin-rosuvastatin conjugate (LF-RST) F2}


First, the addition of DIC $(0.019 \mathrm{~mL}, 0.12 \mathrm{mmol})$ and Oxyma $(0.017 \mathrm{~g}, 0.12 \mathrm{mmol})$ to $(0.025 \mathrm{~g}, 0.025 \mathrm{mmol})$ calcium salt of RST solution in $5 \mathrm{~mL}$ DMSO was carried out. Then, RST was preactivated at RT for $10 \mathrm{~min}$ to completely convert the carboxylate group to the corresponding active ester. $(0.10 \mathrm{~g}, 0.00125 \mathrm{mmol})$ Lactoferrin dissolved in DMSO $(5 \mathrm{~mL})$ was added dropwise to the reaction mixture and stirred overnight at RT. Dialysis was performed on the resulting solution against DMSO for $24 \mathrm{~h}$, and the dialysate was collected to indirectly determine the RST content. Then, dialysis of the reaction mixture against double filtrated distilled $\mathrm{H}_{2} \mathrm{O}$ was carried out by gradually changing the DMSO and $\mathrm{H}_{2} \mathrm{O}$ ratio $(90: 10,70: 30,50: 50,30: 70$, and 10:90) for $72 \mathrm{~h}$. Further dialysis of the reaction mixture was carried out against double filtrated distilled $\mathrm{H}_{2} \mathrm{O}$ followed by lyophilization.

\subsubsection{Preparation of alginate/lactoferrin-rosuvastatin nanohybrids loaded with honokiol (HK-loaded ALG/LF-RST NHs) F4}

Sodium alginate (ALG, $0.05 \mathrm{~g}$ ) was dissolved in $7 \mathrm{~mL}$ double filtrated distilled $\mathrm{H}_{2} \mathrm{O}$. The activation of the carboxylic group of ALG was carried out by the in situ addition of $0.009 \mathrm{~g}(0.05 \mathrm{mmol}) \mathrm{K}$. Oxyma and $0.01 \mathrm{~g}(0.05 \mathrm{mmol}) \mathrm{EDC}$. HCl at RT under constant stirring for $5 \mathrm{~min}$. The prepared aqueous solution of LF-RST conjugate $(12 \mathrm{~mL}, 0.116 \mathrm{~g}$, Section 2.2.2) was then added dropwise to the activated ALG solution. The reaction was stirred at RT for $24 \mathrm{~h}$. The resultant nanohybrids were dialyzed against double filtrated distilled water to obtain ALG/LF-RST NHs F3. The solvent evaporation method was adopted for the physical loading of HK into the core of ALG-LF-RST NHs. An amount of $0.015 \mathrm{~g}$ of HK was dissolved in $0.3 \mathrm{~mL}$ ethyl alcohol, added to ALG/LF-RST $\mathrm{NH}$ colloidal solution, and stirred overnight to allow slow evaporation of the organic solvent and physical loading of the drug within the hydrophobic core of the nanohybrids. Finally, the product was centrifuged at $4^{\circ} \mathrm{C}$ for $10 \mathrm{~min}$, filtrated to eliminate unentrapped drug and lyophilized.

\subsubsection{Preparation of Pemetrexed-Alginate conjugate (PMT-ALG) F5}

K. Oxyma $(0.018 \mathrm{~g}, 0.1 \mathrm{mmol})$ and EDC. $\mathrm{HCl}(0.02 \mathrm{~g}, 0.1 \mathrm{mmol})$ and were added to $(0.015 \mathrm{~g}, 0.035 \mathrm{mmol})$ PMT solution in $5 \mathrm{~mL}$ double filtrated distilled $\mathrm{H}_{2} \mathrm{O}$. Then, the addition of the prepared ALG solution ( $0.05 \mathrm{~g}$ of ALG dissolved in $7 \mathrm{~mL}$ double filtrated distilled $\mathrm{H}_{2} \mathrm{O}$ ) to the reaction mixture was performed and stirred overnight at RT. The reaction mixture was dialyzed against double filtrated distilled $\mathrm{H}_{2} \mathrm{O}$ for $24 \mathrm{~h}$. Then, the dialysate was collected to determine the unconjugated PMT, followed by successive replacement of distilled $\mathrm{H}_{2} \mathrm{O}$ for an additional $48 \mathrm{~h}$, followed by lyophilization.

\subsubsection{Preparation of pemetrexed-alginate/lactoferrin nanohybrids loaded with honokiol (HK-loaded PMT-ALG/LF NHs) F7}

The PMT-ALG conjugate aqueous solution $(13 \mathrm{~mL}, 0.062 \mathrm{~g}$, prepared as described in Section 2.2.4) was further preactivated for 5 min using $(0.01 \mathrm{~g}, 0.05 \mathrm{mmol}) \mathrm{EDC}$. $\mathrm{HCl}$ and $0.009 \mathrm{~g}(0.05 \mathrm{mmol}) \mathrm{K}$. Oxyma at RT under constant stirring. An aqueous solution (5 $\mathrm{mL}$ ) of lactoferrin $(0.10 \mathrm{~g}, 0.00125 \mathrm{mmol})$ was added dropwise to the reaction mixture, which was stirred for $24 \mathrm{~h}$ at RT. The resultant PMT-ALG/LF NHs F6 were then purified by dialysis against double filtrated distilled water. The solvent evaporation method was adopted for the physical loading of $0.015 \mathrm{~g}$ of HK in $0.3 \mathrm{~mL}$ ethanol into the core of PMT-ALG/LF nanohybrids, as presented previously in Section 2.2.3. The newly prepared NHs were lyophilized for further characterization.

\subsubsection{Preparation of pemetrexed-alginate/lactoferrin-rosuvastatin nanohybrids (PMT-ALG/LF-RST NHs) F8}

The PMT-ALG conjugate aqueous solution ( $13 \mathrm{~mL}, 0.062 \mathrm{~g}$, prepared as described in Section 2.2.4) was preactivated for $5 \mathrm{~min}$ by $(0.01 \mathrm{~g}, 0.05 \mathrm{mmol}) \mathrm{EDC}$. $\mathrm{HCl}$ and $0.009 \mathrm{~g}(0.05 \mathrm{mmol}) \mathrm{K}$. Oxyma at RT under constant stirring. The aqueous solution of the LFRST conjugate ( $12 \mathrm{~mL}, 0.116 \mathrm{~g}$, prepared as given in Section 2.2.2) was then added dropwise to the reaction mixture and stirred overnight at RT. The resultant nanohybrids were then dialyzed against double filtrated distilled $\mathrm{H}_{2} \mathrm{O}$ and lyophilized for further characterization.

\subsubsection{Physical loading of HK within PMT-ALG-LF-RST nanohybrids (HK-loaded PMT-ALG/LF-RST NHs) F9}

The solvent evaporation method was used to load HK into the core of PMT-ALG/LF-RST NHs F8. An amount of $0.015 \mathrm{~g}$ of HK dissolved in $0.3 \mathrm{~mL}$ ethanol was added to $27 \mathrm{~mL}$ ( $0.178 \mathrm{~g}$ equivalent to $0.016 \mathrm{~g} \mathrm{RST}, 0.012 \mathrm{~g}$ PMT and $0.014 \mathrm{~g} \mathrm{HK})$ of the prepared PMT-ALG/LF-RST NHs F8. The resulting colloidal solution was treated as described previously in Section 2.2.3, followed by lyophilization. 


\subsubsection{Crosslinking of HK-loaded PMT-ALG/LF-RST nanohybrids (crosslinked HK-loaded PMT-ALG/LF-RST NHs) F10}

Genipin $(0.035 \mathrm{~g}, 0.155 \mathrm{mmol})$ was added to $22 \mathrm{~mL}(0.192 \mathrm{~g}$ equivalent to $0.016 \mathrm{~g} \mathrm{RST}, 0.012 \mathrm{~g}$ PMT and $0.014 \mathrm{~g} \mathrm{HK})$ of the prepared HK/PMT-ALG/LF-RST NHs F9 and left for $48 \mathrm{~h}$ under constant stirring to achieve particle crosslinking. The prepared colloidal crosslinked HK/PMT-ALG/LF-RST NHs F10 were freeze dried to obtain a blue powder.

\subsection{Physicochemical characterization of crosslinked HK-loaded PMT-ALG/LF-RST NHs}

Many methods have been performed to estimate the physicochemical characteristics of the synthesized nanohybrids. Loading and conjugation of drugs were studied via DSC, HPLC, FT-IR and ${ }^{1} \mathrm{H}-\mathrm{NMR}$ spectroscopy. The release of drugs was investigated via the dialysis membrane method and HPLC, while the zeta potential and particle size were measured utilizing a Malvern Zetasizer, and the particle morphology was investigated by TEM. Additionally, the dispersibility and stability of the synthesized nanohybrids were investigated thoroughly. In addition, lyophilization, redispersibility, physical stability testing, in vitro hemolysis and serum stability were performed as detailed in the Supporting information (SI).

\subsection{In vitro cytotoxicity and cellular uptake study}

The cytotoxicity of free HK, free RST, free PMT, free PMT/RST combination, free PMT/HK combination, free HK/RST combination, free RST/PMT/HK combination, HK-loaded ALG/LF-RST NHs F4, HK-loaded PMT-ALG/LF NHs F7, PMT-ALG/LFRST NHs F8, HK-loaded PMT-ALG/LF-RST NHs F9, and crosslinked HK-loaded PMT-ALG/LF-RST NHs F10 on MCF-7 breast cancer cells was investigated by the MTT assay detailed in the SI. The intensity of cellular uptake was compared to uncrosslinked PMT-ALG/LF-RST and crosslinked PMT-ALG/LF-RST NHs using flow cytometry (details in SI). The cellular uptake of uncrosslinked PMT-ALG/LF-RST and crosslinked PMT-ALG/LF-RST NHs into MCF-7 cancer cells was investigated by confocal microscopy as described in the SI.

\subsection{In vivo antitumor efficacy}

The in vivo antitumor efficacy of crosslinked HK-loaded PMT-ALG/LF-RST NHs F10 was compared with free RST, free HK, free PMT and free (HK/RST/PMT) combination therapy solution using female mice in accordance with the standard protocol described in the SI.

\section{Results And Discussion}

\subsection{Synthesis of PMT-ALG/LF-RST NHs F8}

In this research, novel ALG/LF NHs were developed via chemical conjugation for the delivery of combined poorly soluble anticancer drugs, such as RST and HK, and the highly soluble cytotoxic drug PMT to breast cancer cells. ALG is a hydrophilic polysaccharide that exists in all types of brown algae. In addition to ALG biodegradability and biocompatibility, the rationale for choosing ALG as a nanoparticle shell is to exploit its stealth property to prevent reticuloendothelial recognition and subsequent removal, thus allowing passive accumulation of the nanoparticles in the tumor. Furthermore, lactoferrin (LF), a member of the Tf family, has established anticancer properties. Moreover, the rationale for choosing LF was to exploit its selective tumor-targeting action by binding to overexpressed multiple receptors in breast tumor cells. The conjugation of chemotherapeutic agents such as PMT and RST to ALG and LF, respectively, can enhance their efficacy and bioavailability and reduce side effects. Thus, RST conjugation to LF would improve its water solubility due to the hydrophilic nature of LF. Additionally, PMT conjugation to ALG would sustain its release in the systemic circulation, hence enabling its targeted delivery into tumor cells. In the current study, PMT-ALG/LF-RST NHs were developed through three steps. First, the LF-RST conjugate was synthesized via the formation of an amide bond via carbodiimide coupling. DIC/Oxyma was used to activate the carboxylic acid side chains of RST; thus, an intermediate Oxyma-activated ester molecule was formed and covalently coupled with the amine groups of LF [25-31]. The LFRST conjugate showed a particle size of $179.0 \mathrm{~nm}$ with high RST loading (15.25 $\pm 0.56 \mathrm{wt} . \%)$ and $\zeta$-potential of $+14.7 \mathrm{mV}$. This is similar to a previous study reported by Abdelmoneem et al., which fabricated an LF-Celastrol (LF-CST) conjugate, where the hydrophilic property of LF was utilized to solubilize the hydrophobic drug.[24] Second, PMT-ALG conjugates were synthesized through ester bond formation by carbodiimide coupling. EDC.HCl/K. Oxyma was used to activate the carboxylic acid side chains 
of PMT to covalently couple with the hydroxyl groups of ALG. The resulting PMT-ALG conjugate showed a particle size of 267.9 $\mathrm{nm}$ with a high PMT loading (19.35 $0.64 \mathrm{wt} . \%$ ) and $\zeta$-potential of $-47.1 \mathrm{mV}$ [25-30]. Recently, polysaccharide drug conjugation was reported by Zhou et al., where dextran-RST was also prepared by a carbodiimide coupling reaction [32]. Third, PMT-ALG/LFRST NHs were fabricated by coupling the PMT-ALG conjugate to the LF-RST conjugate through the formation of an amide bond by utilizing coupling reagents such as K. Oxyma and EDC. HCL, which enables the covalent coupling of free carboxylic acids of the PMT-ALG conjugate with the free amino groups of the LF-RST conjugate [25-30]. These newly synthesized nanohybrids can self-assemble into spherical nanohybrids consisting of an LF-RST conjugate inner core as a reservoir for hydrophobic drugs and a PMT-ALG conjugate as a hydrophilic shell, where conjugation of RST to the LF polymer could also increase the hydrophobicity of LF [33] [34]. In our preliminary study, two conjugation ratios between ALG and LF were investigated for the preparation of ALG/LF NHs (Table 1). The ALG:LF (1:2) ratio was finally selected based on zeta potential and particle size characterization. The resultant PMT-ALG/LF-RST NHs exhibited a particle size of $304.9 \mathrm{~nm}$ and a greatly negative $\zeta$-potential of $-43.8 \mathrm{mV}$, which might correspond to the free $\mathrm{COOH}$ groups of ALG on the surface of the copolymer (Table 1). The preparation steps of crosslinked HKloaded PMT-ALG/LF-RST NHs are illustrated in the schematic diagram shown in Fig. 1.

Table 1. Physicochemical Characteristics and Composition of Crosslinked HK/PMT-ALG-LF-RST NHs. Zeta potential, particle size, entrapment efficiency (EE), drug loading (DL), and conjugation efficiency (CE \%) of NPs $(n=3)$ :

\begin{tabular}{|c|c|c|c|c|c|c|c|c|c|c|}
\hline & \multirow[t]{2}{*}{ Formula } & \multirow{2}{*}{$\begin{array}{l}\text { Particle } \\
\text { size }(n m)\end{array}$} & \multirow[t]{2}{*}{ PDI } & \multirow{2}{*}{$\begin{array}{l}\text { 3-potential } \\
\text { (mV }\end{array}$} & \multicolumn{2}{|l|}{ RST } & \multicolumn{2}{|l|}{ PMT } & \multicolumn{2}{|l|}{ HK } \\
\hline & & & & & $\begin{array}{l}\text { DL } \\
\text { (mg/wt.\%) }\end{array}$ & $\% \mathrm{CE}$ & $\begin{array}{l}\text { DL } \\
\text { (mg/wt.\%) }\end{array}$ & $\% \mathrm{CE}$ & $\begin{array}{l}\text { DL } \\
\text { (mg/wt.\%) }\end{array}$ & $\% \mathrm{EE}$ \\
\hline $\mathrm{F} 1$ & ALG/LF (1:1) & $220.6 \pm 1.8$ & 0.383 & $-47.1 \pm 0.41$ & & & - & - & - & - \\
\hline $\mathrm{F} 1$ & ALG/LF (1:2) & $163.9 \pm 2.3$ & 0.342 & $-41.1 \pm 0.53$ & - & - & - & - & - & - \\
\hline $\mathrm{F} 2$ & LF-RST & $179.0 \pm 1.3$ & 0.371 & $+14.7 \pm 0.91$ & $16 / 13.79$ & 64.0 & - & - & - & - \\
\hline F3 & ALG/LF-RST & $239.0 \pm 1.8$ & 0.348 & $-43.8 \pm 0.27$ & $16 / 9.63$ & 64.0 & - & - & - & - \\
\hline F4 & $\begin{array}{l}\text { HK-loaded } \\
\text { ALG/LF RST }\end{array}$ & $365.2 \pm 2.1$ & 0.347 & $-46.9 \pm 0.65$ & $16 / 8.89$ & 64.0 & - & - & $14 / 7.69$ & 93.3 \\
\hline F5 & ALG-PMT & $267.9 \pm 1.2$ & 0.458 & $-47.1 \pm 0.72$ & - & - & $12 / 19.35$ & 80.0 & - & - \\
\hline F6 & PMT-ALG/LF & $224.8 \pm 1.6$ & 0.367 & $-39.7 \pm 0.39$ & - & - & $12 / 7.40$ & 80.0 & - & - \\
\hline F7 & $\begin{array}{l}\text { HK-loaded } \\
\text { PMT-ALG/LF }\end{array}$ & $333.0 \pm 1.9$ & 0.410 & $-41.2 \pm 0.83$ & - & - & $12 / 6.81$ & 80.0 & $14 / 7.95$ & 93.3 \\
\hline F8 & $\begin{array}{l}\text { PMT-ALG/LF- } \\
\text { RST }\end{array}$ & $304.9 \pm 2.7$ & 0.464 & $-43.8 \pm 0.56$ & $16 / 8.98$ & 64.0 & $12 / 6.67$ & 80.0 & - & - \\
\hline F9 & $\begin{array}{l}\text { Uncrosslinked } \\
\text { HK loaded } \\
\text { PMT-ALG/LF- } \\
\text { RST }\end{array}$ & $389.7 \pm 1.5$ & 0.423 & $-44.7 \pm 0.32$ & $16 / 8.33$ & 64.0 & $12 / 6.18$ & 80.0 & $14 / 7.21$ & 93.3 \\
\hline F10 & $\begin{array}{l}\text { Crosslinked } \\
\text { HK-loaded } \\
\text { PMT-ALG/LF- } \\
\text { RST }\end{array}$ & $258.7 \pm 0.95$ & 0.342 & $-45.3 \pm 0.47$ & $16 / 7.05$ & 64.0 & $12 / 5.24$ & 80.0 & $14 / 6.11$ & 93.3 \\
\hline
\end{tabular}

The conjugation reactions were confirmed by ${ }^{1} \mathrm{H}-\mathrm{NMR}$ analysis (Fig. 2). The ${ }^{1} \mathrm{H}-\mathrm{NMR}$ spectrum of LF in DMSO- $d_{6}$ (Fig. 2B) shows multiplet peaks at the variation between 0.50 and $2.40 \mathrm{ppm}$ attributed to the peptide chain aliphatic protons of LF. Moreover, two broad multiplet peaks were observed at 6.60-6.70 and 7.10-7.30 ppm, attributed to the peptide chain aromatic protons and $\mathrm{NH}$ protons. The ${ }^{1} \mathrm{H}$-NMR spectrum of the LF-RST conjugate (Fig. $2 \mathrm{~A}$ ) reveals a broad singlet peak at $1.25 \mathrm{ppm}$ attributed to the methyl groups of RST. In addition, 2 singlet peaks at 2.74 and 2.91 ppm corresponding to the $\mathrm{S}-\mathrm{CH}_{3}$ and N-CH groups of RST, 
respectively, were observed. Additionally, multiplet peaks attributed to the aromatic protons of RST are observed in the range of 6.90-8.00 ppm. On the other hand, the ${ }^{1} \mathrm{H}-\mathrm{NMR}$ spectrum of $\mathrm{ALG}$ in $\mathrm{D}_{2} \mathrm{O}$ (Fig. 2E) shows multiplet peaks in the range 3.64-4.16 ppm. The ${ }^{1} \mathrm{H}-\mathrm{NMR}$ spectrum of the ALG-PMT conjugate in $\mathrm{D}_{2} \mathrm{O}$ (Fig. 2D) shows peaks in the range of 1.70-3.10 ppm, characteristic of the methylene protons of PMT. Moreover, multiplet peaks were observed in the range of 7.81-7.82 ppm related to the aromatic protons of PMT. The ${ }^{1} \mathrm{H}-\mathrm{NMR}$ spectrum of PMT-ALG-LF-RST NHs (Fig. 2C) shows 3 multiplet peaks in the range of 0.80-1.23 ppm attributed to the aliphatic protons of the LF-RST conjugate. Furthermore, peaks in the range of 1.70-3.10 ppm were observed to be characteristic of the methylene protons of PMT. Moreover, multiplet peaks attributed to the alginate aliphatic $\mathrm{C}-\mathrm{H}$ protons were observed in the range of 3.64-4.00 ppm.

\subsection{Development of crosslinked HK-loaded PMT-ALG/LF-RST NHs}

In contrast to PMT and RST, which were covalently coupled to the ALG-LF backbone, HK was physically loaded inside the hydrophobic core of PMT-ALG/LF-RST NHs via a simple solvent evaporation method. There may be an abundance of co-acting intermolecular interactions between the carrier material and the drug in the loading process, such as van der Waal forces, hydrophobic interactions and hydrogen bonding. All of these forces can play a role in effective HK loading and nanohybrid stabilization [35, 36]. Finally, the crosslinking of polymeric nanohybrids with genipin seems to be an excellent strategy to enhance their structural stability and prevent rapid drug release and premature disintegration. This study revealed that genipin successfully crosslinked the amine groups of LF with a significant reduction in the nanohybrid size and drug release profile. The crosslinking reaction by genipin led to the appearance of an intense blue color. Upon crosslinking of nanohybrids, the particle size markedly decreased from $389 \mathrm{~nm}$ to $258.7 \mathrm{~nm}$ by virtue of forming more compact and denser nanohybrids (Table 1 and Fig. 3A, B) [37]. During our preliminary investigations, different amounts of genipin were used for the crosslinking of ALG-LF nanohybrids (Table 2). Approximately $35 \mathrm{mg}$ (1:5.54 wt. ratio) of genipin was finally selected based on PS and PDI characterization.

Table 2. Effect of genipin amounts on zeta potential, PDI and particle size of nanohybrids F10 $(n=3)$ :

\begin{tabular}{|llll|}
\hline Amount of genipin $(\mathrm{mg})$ & $\begin{array}{l}\text { F9: genipin } \\
\text { wt. ratio }\end{array}$ & particle size $(\mathrm{nm})$ & PDI \\
\hline 10 & $1: 19.4$ & $389.0 \pm 0.30$ & 0.450 \\
\hline 20 & $1: 9.7$ & $320.0 \pm 0.60$ & 0.410 \\
\hline 30 & $1: 6.46$ & $290.0 \pm 0.87$ & 0.360 \\
\hline 50 & $1: 5.54$ & $258.7 \pm 0.95$ & 0.342 \\
\hline
\end{tabular}

* The amount of HK-loaded PMT-ALG/LF-RST NHs F9 used is $194 \mathrm{mg}$.

\subsection{Solid-State Characterization.}

The FT-IR spectra of our prepared formulations were used to study the chemical modification (Fig. 3C). The FT-IR spectrum of the LF-RST conjugate shows two bands at 1317 and $1151 \mathrm{~cm}^{-1}$ attributed to the $\mathrm{SO}_{2}$ group of RST. Additionally, a band at $1540 \mathrm{~cm}^{-}$

${ }^{1}$ specific to the $\mathrm{C}=\mathrm{N}$ group of RST was observed. Furthermore, LF characteristic absorption bands ranging between 3600-2600 $\mathrm{cm}^{-1}$ are assigned to $\mathrm{N}-\mathrm{H}$ and hydroxyl groups, where bands at $2961 \mathrm{~cm}^{-1}$ and $2865 \mathrm{~cm}^{-1}$ assigned to the sp $\mathrm{C}^{3} \mathrm{H}$ stretching vibration were observed. Additionally, the most distinctive bands of LF at 1651 (amide I) and 1448 (amide II) $\mathrm{cm}^{-1}$ were observed. The new amidic carbonyl group in the LF-RST conjugate overlapped with that of LF at $1651 \mathrm{~cm}^{-1}$, which confirms amide bond formation between LF and RST. On the other hand, the FT-IR spectrum of the ALG-PMT conjugate (Fig. 3C) showed a broad stretching band in the range 3300 to $3000 \mathrm{~cm}^{-1}$ attributed to the hydroxyl group of ALG. Furthermore, the disappearance of the strong band of PMT at $1690 \mathrm{~cm}^{-1}$ and the broad band ranging between $3600-2500 \mathrm{~cm}^{-1}$ attributed to 
carboxylic acid confirms PMT conjugation. Moreover, a stretching band at $1701 \mathrm{~cm}^{-1}$ related to the new ester carbonyl group in the PMT-ALG conjugate was observed.[33] In addition, the FT-IR spectrum of PMT-ALG-LF-RST NHs (Fig. 3C) shows an absorption band at $1652 \mathrm{~cm}^{-1}$, corresponding to the new amide carbonyl group of the nanohybrids overlapped with that of the LF and LF-RST conjugates at $1651 \mathrm{~cm}^{-1}$. Moreover, an absorption band at $1302 \mathrm{~cm}^{-1}$ attributed to the $\mathrm{SO}_{2}$ group of RST was observed. The band at $1542 \mathrm{~cm}^{-1}$ related to the $\mathrm{C}=\mathrm{N}$ group of RST was also noticed. In addition, the FT-IR spectrum of HK-loaded PMT-ALG/LF-RST NHs reveals a broad absorption band at $3292 \mathrm{~cm}^{-1}$, which is related to the OH group of HK. This band overlapped with the broad band between $3600-2500 \mathrm{~cm}^{-1}$ corresponding to $\mathrm{N}-\mathrm{H}$ and hydroxyl groups characteristic of $\mathrm{LF}$ and the hydroxyl group corresponding to ALG. Moreover, two absorption bands at $1639 \mathrm{~cm}^{-1}$ and $1426 \mathrm{~cm}^{-1}$ assigned to the phenyl ring of HK were observed. This absorption band $\left(1639 \mathrm{~cm}^{-1}\right)$ is overlapped by the amidic carbonyl group of the copolymer at 1652 $\mathrm{cm}^{-1}$. Additionally, an absorption band at $3084 \mathrm{~cm}^{-1}$ attributed to the $\mathrm{sp}^{2} \mathrm{C}-\mathrm{H}$ stretching band of $\mathrm{HK}$ was observed. The absorption band at $1217 \mathrm{~cm}^{-1}$ related to the $\mathrm{C}-\mathrm{O}$ bond of HK was also observed. The FT-IR spectrum of crosslinked HK-loaded PMT-ALG/LF-RST NHs (Fig. 3C) shows the characteristic absorption bands of genipin, which appear in the fingerprint region of the spectrum. Moreover, a very broad absorption band between $3600-2600 \mathrm{~cm}^{-1}$ was attributed to $\mathrm{N}-\mathrm{H}$ and hydroxyl groups characteristic of LF, and the hydroxyl groups of ALG were observed.

The DSC thermograms of RST revealed endothermic peaks at approximately $80^{\circ} \mathrm{C}$ and $164^{\circ} \mathrm{C}$, which were assigned to the drug melting temperature (Fig 4A) [38]. The thermogram of PMT showed three distinctive endothermic peaks at 91.78, 153.82 and $243.80^{\circ} \mathrm{C}$ [39]. The characteristic peaks of RST and PMT are not observed in the PMT-ALG/LF-RST NHs F8 thermogram, which emphasizes the amorphous nature of these $\mathrm{NHs}$ [24]. Additionally, the natural state of HK exists in a crystalline form and reveals its melting peak at approximately $72.43^{\circ} \mathrm{C}$. The DSC thermogram of HK-loaded PMT-ALG/LF-RST NHs F9 showed only an endothermic peak at $341.29^{\circ} \mathrm{C}$, confirming the loading of $\mathrm{HK}$ within $\mathrm{NHs}$ in an amorphous form [40].

\subsection{Morphological analysis, physical stability and redispersibility}

The TEM micrograph of crosslinked HK-loaded PMT-ALG/LF-RST NHs F10 showed a spherical shape with a diameter range of 141-233 nm with no agglomerated particles, confirming their elevated colloidal stabilization (Fig. 4B). The TEM images also exhibited the formation of a distinctive core-shell structure composed of the hydrophilic corona of PMT-ALG surrounding the hydrophobic core of LF-RST. It was also noticed that after storage for 3 months at $4^{\circ} \mathrm{C}$, both HK-loaded PMT-ALG/LF-RST NHs F9 and crosslinked HK-loaded PMT-ALG/LF-RST NHs F10 maintained their PSs of $410 \pm 1.9$ and $268 \pm 0.3 \mathrm{~nm}$, respectively, without a significant difference from the NHs that were initially stored, indicating their fair stability (Fig. 4C). The high zeta potential (-45.3 and $-44.7 \mathrm{mV}$ ) of both F9 and F10 NHs may explain their great stability, as ALG negatively charged side chains induce strong repulsive forces between $\mathrm{NHs}$. In addition to the repulsion mechanism, stabilization of the NHs may be enhanced by the glycan chain of LF by improving the interdomain interactions of LF and protecting against protein degradation [41, 42]. The physical stability of the NHs can be further improved by lyophilization of the prepared NHs into a dry powder [43]. In our research, no cryoprotectant was needed, and a fluffy powder was obtained that could be redispersed in $\mathrm{H}_{2} \mathrm{O}$, forming a colloidal solution with no aggregation. The reconstituted lyophilized F9 and F10 NHs demonstrated PS of $380 \pm 0.8$ and $250 \pm 0.8 \mathrm{~nm}$ with redispersibility index values of 0.966 and 0.975 , respectively, where values less than 1.0 are considered efficient $[44,45]$. Furthermore, the zeta potential of the NHs after lyophilization did not markedly change (Table 3).

Table 3. Freeze-drying effect on the PS, zeta potential and yield of F9 and F10 NHs $(n=3)$ :

\begin{tabular}{|c|c|c|c|c|c|c|}
\hline \multirow[t]{2}{*}{ Formula } & \multirow{2}{*}{$\begin{array}{l}\text { Yield }(\% \\
\text { w/w) }\end{array}$} & \multicolumn{2}{|l|}{ PS (nm) } & \multirow{2}{*}{$\begin{array}{l}\mathrm{RI}^{*} \\
(\mathrm{Sf} / \mathrm{Si})\end{array}$} & \multicolumn{2}{|c|}{$\zeta$-potential (mV) } \\
\hline & & Before & After & & Before & After \\
\hline HK-loaded PMT-ALG/LF-RST NHs F9 & $92.3 \%$ & $389.7 \pm 0.5$ & $380.0 \pm 1.2$ & 0.975 & $-44.7 \pm 1.3$ & $-45.0 \pm 0.6$ \\
\hline $\begin{array}{l}\text { Crosslinked HK-loaded PMT-ALG/LF-RST NHs } \\
\text { F10 }\end{array}$ & $94.4 \%$ & $258.7 \pm 0.9$ & $250.0 \pm 0.8$ & 0.966 & $-45.3 \pm 0.5$ & $-46.1 \pm 0.7$ \\
\hline
\end{tabular}

* Rl: Redispersibility index (Final particle size / Initial particle size) 


\subsection{In vitro drug release:}

The in vitro release of PMT, RST and HK from uncrosslinked HK-loaded PMT-ALG/LF-RST NHs F9 and crosslinked HK-loaded PMT-ALG/LF-RST NHs F10 was evaluated at pH 4, 5.5 and 7.4 using the dialysis method in PBS (Fig. 5 B). A, B). The results revealed that $\mathrm{HK}$ release from $\mathrm{NHs}$ at $\mathrm{pH} 4,5.5$ and 7.4 did not differ significantly. The release profile of HK loaded in NHs was biphasic with a fast release during the first $8 \mathrm{~h}$ (approximately $30 \%$ and 18.5\% from F9 and F10 NHs, respectively) followed by slow release (with approximately $55.5 \%$ and $34 \%$ from $\mathbf{F 9}$ and $\mathbf{F} 10 \mathrm{NHs}$, respectively) for the remaining $120 \mathrm{~h}$. Early rapid release can be ascribed to the fact that part of the drug is localized at the shell or the core-shell interface, but the slow-release phase of the drug can be due to that part of the drug entrapped physically in the hydrophobic core of the nanohybrids [46]. Typically, the release rate of $\mathrm{HK}$ from crosslinked NHs F10 is slower than the rate from uncrosslinked NHs F9, as the degree of nanostructural tortuosity was enhanced and the space between polymer chains was reduced by crosslinking [47]. Unlike HK, the results showed that crosslinking had no effect on PMT release. PMT showed a sustained release from the $\mathrm{NHs}$ at pH 4, reaching $40 \%$ over 5 days as the ester bond can be hydrolyzed in acidic medium, while the release decreased at pH 5.5 (approximately 5\%), and no release was detected at $\mathrm{pH} 7.4$ over the entire period of the experiment. The PMT release was very low due to the need for ester bond cleavage for enzymatic or chemical degradation. Our results are consistent with the previously mentioned in vitro drug release investigation, which was performed on DTX-polymer conjugate, where the conjugate released approximately $15 \%$ over 20 days of DTX under physiological circumstances ( $\mathrm{pH}$ 7.4) and slightly higher in acidic environments [48]. On the other hand, even after long-term incubation at acidic pH, RST release from F9 and F10 NHs could not be detected. This is expected for RST, which was coupled by a highly stable amide bond that would only be cleavable inside the cancer cells under the effect of the endosomal enzymes. Markovsky et al. reported similar results after extended incubation at acidic $\mathrm{pH}$, where no in vitro release of doxorubicin from PGA-paclitaxel-doxorubicin conjugate was observed [49]. The slow release of the drug from the developed $\mathrm{NHs}$ would enable them for parenteral administration due to their stability at physiological $\mathrm{pH}$, allowing improved drug accumulation and localized drug release at the site of the tumors [50].

\subsection{Hemocompatibility and serum stability}

The stabilization of intravenous nanoformulations in serum is important in their drug delivery application. Nanohybrids F9 and F10 showed no significant change in their particle size (from $389.7 \pm 0.5$ to $396 \pm 1.2 \mathrm{~nm}$ and from $258.7 \pm 0.95$ to $260 \pm 1.7 \mathrm{~nm}$, respectively) when mixed with fetal bovine serum (FBS) (Fig. 5C). This could be attributed to the hydrophilic brush-like structure of the ALG shell of NHs that leads to minimal protein adsorption on $\mathrm{NHs}$, in addition to the hydrophobic core protection from biological invasion [51] and surface passivation of nanohybrids. Elevated stability of NHs in serum might be due to repulsion force between the serum proteins having negative charges and the prepared nanohybrids. After incubation for $4 \mathrm{~h}$ with FBS, the particle sizes of F9 and F10 NHs reached $407 \pm 0.2 \mathrm{~nm}$ and $275 \pm 1.2 \mathrm{~nm}$, respectively, which decreased to $396 \pm 1.2 \mathrm{~nm}$ and 260 $\pm 1.7 \mathrm{~nm}$ after $6 \mathrm{~h}$. This action might be attributed to protein molecule association and dissociation on the NH surface through incubation [52].

On another avenue, the hemolytic activity of $\mathbf{F 9}$ and $\mathbf{F} 10 \mathrm{NHs}$ was approximately $3.7 \%$ and $3.3 \%$, respectively, up to a $1 \mathrm{mg} / \mathrm{mL}$ concentration (Fig. 5D, E). In general, the nontoxic and safe percentage of hemolytic activity is less than 5\% [53]. Our prepared NHs exhibited acceptable hemolytic activity by virtue of surface passivation of NHs by incorporation of ALG polymer to suppress protein and cell attachment to the surface of $\mathrm{NHs}$ [54]. These results indicated that F9 and F10 NHs have good hemocompatibility and are suitable for parenteral administration.

\subsection{In vitro cytotoxicity}

The efficiency of the free PMT, free RST, free HK, free dual combinations (RST/HK, PMT/RST, PMT/HK) and free triple combinations (PMT/RST/HK) against cancer was studied on MCF-7 breast cancer cells compared to the developed nanohybrids after $24 \mathrm{~h}$ of exposure using the MTT assay (Fig. 6A, B). First, the noncytotoxicity of blank ALG/LF NHs against MCF-7 cells after $24 \mathrm{~h}$ was confirmed, indicating their safety and biocompatibility $\left(\mathrm{IC}_{50}=3095.443\right)$. Compared to free single and free dual drugs, free combination therapy (PMT/RST/HK) displayed higher cytotoxicity, revealing the synergistic effect between the three drugs. Regarding the nanohybrids, it seemed that dual drug-loaded nanohybrids (HK loaded-ALG/LF-RST NHs F4, PMT-ALG/LF-RST NHs F8 and HK loaded-PMT-ALG/LF NHs F7) improved the potency of the combination, showing $I_{50}$ values with $0.61-$, $0.46-$, and 
0.44-fold reductions compared to free combination therapy (PMT/RST/HK), respectively. On the other hand, the crosslinked HK/PMT-ALG-LF-RST NHs F10 revealed the minimum IC 50 value in comparison to the other prepared NHs.

CompuSyn software mentioned by Chou and Talalay was utilized to perform more extensive statistical analysis [55-57]. The dose reduction index (DRI) and combination index $(\mathrm{Cl})$ were estimated to assess the antitumor efficiency of the prepared $\mathrm{NHs}$ relative to the free combination therapy (Table 4). The outputs showed that, compared to the free drug combination, all prepared NHs had higher anticancer activity, especially uncrosslinked and crosslinked HK-loaded PMT-ALG/LF-RST NHs F9 and F10, where their Cls were 0.0556 and 0.0336 , respectively, supporting the synergism accomplished by triple loading of PMT/RST/HK in NHs. Moreover, the dose reduction index (DRIs) of PMT were 51.22 and 84.84 in F9 and F10 NHs, respectively. The RST DRIs were 36.85 and 61.04 in the F9 and F10 NHs, respectively. The DRIs of HK were 111.3 and 184.34 in the F9 and F10 NHs, respectively.

Table 4. $\mathrm{Cl}_{1} \mathrm{IC}_{50}$, and DRI values of free drugs in comparison to the synthesized NHs against MCF-7 breast cancer cells after $24 \mathrm{~h}$ at concentrations of $0-100 \mu \mathrm{M}$

\begin{tabular}{|c|c|c|c|c|c|c|c|c|}
\hline Compound & $\begin{array}{l}\mathrm{Cl} \\
\text { value }\end{array}$ & $\begin{array}{l}\text { Total IC } \mathrm{C}_{50} \text { of } \\
\text { Combination }\end{array}$ & $\begin{array}{l}\text { Dose } \\
\text { PMT }\end{array}$ & $\begin{array}{l}\text { Dose } \\
\text { RST }\end{array}$ & $\begin{array}{l}\text { Dose } \\
\text { HK }\end{array}$ & $\begin{array}{l}\text { DRI of } \\
\text { PMT }\end{array}$ & $\begin{array}{l}\text { DRI of } \\
\text { RST }\end{array}$ & $\begin{array}{l}\text { DRI of } \\
\mathrm{HK}\end{array}$ \\
\hline HK & - & 54.95 & - & - & - & - & - & - \\
\hline RST & - & 27.93 & - & - & - & - & - & - \\
\hline PMT & - & 19.22 & - & - & - & - & - & - \\
\hline RST/HK & 0.691 & 23.31 & - & 14.52 & 9.08 & - & 1.93 & 5.81 \\
\hline PMT/RST & 0.672 & 16.31 & 5.46 & 10.93 & - & 3.55 & 2.56 & - \\
\hline PMT/HK & 0.481 & 14.18 & 6.40 & & 8.00 & 3.03 & & 6.58 \\
\hline PMT/RST/HK & 0.286 & 7.97 & 1.96 & 3.91 & 2.44 & 9.94 & 7.15 & 21.59 \\
\hline HK-loaded ALG/LF-RST NHs F4 & 0.142 & 4.90 & - & 2.99 & 1.86 & - & 9.36 & 28.26 \\
\hline HK-loaded PMT-ALG/LF NHs F7 & 0.114 & 3.50 & 1.52 & - & 1.91 & 12.73 & - & 27.66 \\
\hline PMT-ALG/LF-RST NHs F8 & 0.149 & 3.65 & 1.21 & 2.43 & - & 16.00 & 11.51 & - \\
\hline $\begin{array}{l}\text { HK-loaded PMT-ALG/LF-RST NHs } \\
\text { F9 }\end{array}$ & 0.055 & 1.63 & 0.38 & 0.76 & 0.47 & 51.22 & 36.86 & 111.30 \\
\hline $\begin{array}{l}\text { Crosslinked HK-loaded PMT- } \\
\text { ALG/LF-RST NHs F10 }\end{array}$ & 0.033 & 0.94 & 0.23 & 0.46 & 0.29 & 84.84 & 61.04 & 184.30 \\
\hline
\end{tabular}

\subsection{In vitro cellular uptake of nanohybrids:}

For nanohybrid fluorescent labeling, the LF core of the nanohybrids was conjugated to the thiocyanate group of RBITC dye via its free amino groups. Confocal microscopy was utilized to evaluate the uptake of RBITC-labeled uncrosslinked PMT-ALG/LF-RST F8 and crosslinked PMT-ALG/LF-RST NHs after incubation with MCF-7 cells at $37^{\circ} \mathrm{C}$ for $4 \mathrm{~h}$ and $24 \mathrm{~h}$ (Fig. 7A). Our results revealed that crosslinked F8 NHs exhibited greater cellular uptake efficacy in comparison to uncrosslinked F8 $\mathrm{NHs}$, as suggested by the powerful intensity of red fluorescence noticed in cells treated with the former. This could be ascribed to the lower particle size of crosslinked F8 facilitating its cellular internalization [58]. The intensity of fluorescence for both $\mathrm{NHs}$ increased after $24 \mathrm{~h}$ of incubation, suggesting that the process of cellular internalization of the prepared nanohybrids is time-dependent. LF actively targets cancer cells through its interaction with LF receptors that are overexpressed on the cancer cell surface and improve the cellular uptake of nanohybrids [59]. The proton sponge effect and swelling properties of ALG have been revealed to mediate cellular uptake [58]. Flow cytometry analysis confirmed the reliability and accuracy of the results, where comparing the fluorescent intensity of cells treated with uncrosslinked F8 NHs to those treated with crosslinked F8 NHs indicated much greater cellular uptake of the crosslinked F8 after $4 \mathrm{~h}$ of incubation with MCF-7 cells, as revealed in Fig 7B, C. 


\subsection{In vivo antitumor efficacy}

\subsubsection{Tumor growth}

The in vivo antitumor effect for crosslinked HK-loaded PMT-ALG/LF-RST NHs F10 compared with free HK, free RST, free PMT and free (HK/RST/PMT) combination treatment was investigated using mice bearing Ehrlich ascites tumors (EAT). The treatment of mouse groups bearing EAT was conducted for three consecutive weeks while monitoring the tumor size during this period. Following treatment, the highest elevation in the tumor size percentage was in the positive control group, which reached $587 \%$. This was higher than those detected in the free HK (205\%), free RST (183\%), free PMT (177\%), free (HK/RST/PMT) combination therapy (125\%) and crosslinked HK-loaded PMT-ALG/LF-RST-treated groups (103\%) (Fig. 8A). Obviously, the greatest anticancer activity was exhibited by crosslinked HK-loaded PMT-ALG/LF-RST NHs F10, as the tumor burden was reduced in the treated mice in comparison to other groups, showing the efficacy of our rationale.

\subsubsection{Biomarkers of Tumor Growth}

Angiogenesis plays a pivotal role in tumor metastasis and progression. Vascular endothelial growth factor (VEGF-1) is a critical factor in tumor angiogenesis. Recently, some investigations have mentioned the antiangiogenic influence of PMT, RST and HK by downregulation of VEGF-1 expression in tumor cells [60-63]. Herein, ELISA was used to evaluate the degree of VEGF-1 protein expression in tumor tissue (Fig. 8B). Using our prepared crosslinked HK loaded-PMT-ALG/LF-RST NHs F10, VEGF levels were reduced successfully by 2.596 -fold, while the free HK/PMT/RST combination reduced VEGF levels only by 1.744 -fold compared to the positive control.

Recent investigations have reported apoptotic effects induced by HK and PMT through the upregulation of caspase-3 expression $[62,64,65]$. In the current investigation, the caspase 3 expression level was estimated in tissue from EAT-bearing mice to evaluate the apoptotic effect. The results revealed that the apoptotic activity in the treated groups was greater than that in the positive control with a considerably elevated caspase-3 expression level. Our prepared crosslinked HK/PMT-ALG-LF-RST NHs F10 succeeded in elevating caspase-3 protein expression levels by 2.769 -fold versus only a 1.659-fold increase for free HK/PMT/RST combination therapy in comparison to the positive control (Fig. 8C). Moreover, immunohistochemical investigation of mice bearing Ehrlich ascites tumor (EAT) confirmed our result, which revealed a marked $(p<0.05)$ increase in the count of caspase 3-positive immune stained cells in HK-treated (37.67 \pm 2.33$)$, RST-treated (38.67 \pm 1.45$)$, PMT-treated (45.00 \pm 4.04$)$, free HK/PMT/RST combination (74.00 \pm 3.21$)$, and crosslinked HK loaded PMT-ALG/LF-RST NHs F10 (92.00 \pm 1.73$)$ mice compared with untreated positive control $(9.33 \pm 0.88)$ mice (Fig. 8D, E).

\subsubsection{Histopathological investigation and Ki67 detection in cancerous tissue}

In untreated positive control mice, the solid mammary tumor showed circumscribed nodules of necrotic pleomorphic neoplastic and poorly differentiated viable cells. The viable neoplastic cells were characterized by prominent, large hyperchromatic nuclei, anisonucleosis, and bipolar to multipolar mitotic division. However, mice treated with free HK, free RST, free PMT, free PMT/HK/RST combination and crosslinked HK loaded-PMT-ALG/LF-RST NHs F10 revealed similar histologic characterization of neoplastic cells with different degrees of necrosis (Fig. 9A). Moreover, HK and PMT have been reported to enhance the death of necrotic cells in different kinds of cancer $[66,67]$. Necrosis scored semiquantitatively in each excised tumor exhibited a significant elevation in the expression percentage in free HK-treated (approximately 25\%), free RST-treated (approximately 25\%), free PMT-treated (approximately 25\%), free PMT/HK/RST combination (approximately 35\%), and crosslinked HK-loaded PMTALG/LF-RST NHs F10 ( $\geq 50 \%$ ) mice compared with untreated control positive mice (approximately 10\%) (Fig. 9B). The degree of Ki-67 immunoexpression in EAT mice was evaluated to assess proliferative activity (Fig. 9C). The proliferation rate was represented by the significant $(p<0.05)$ decrease in the count of Ki67-immunoreactive cells in HK-treated $(46.00 \pm 2.65)$, RSTtreated (48.33 \pm 2.33$)$, PMT-treated (40.33 \pm 2.03$)$, free (PMT/HK/RST) combination (26.67 \pm 5.04$)$, and crosslinked HK loaded-PMT-

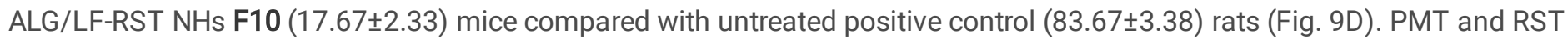
have been reported to lower the density of the tumor cell proliferation protein Ki-67 [68, 69].

\section{Conclusion}


Herein, crosslinked HK-loaded PMT-ALG/LF-RST NHs F10 were developed to deliver a combination of poorly soluble RST and HK and highly soluble PMT anticancer drugs for targeted breast cancer treatment. PMT and RST drugs were conjugated to ALG and LF polymers, respectively, by a carbodiimide conjugation reaction to form an ester bond between ALG and PMT and an amide bond between LF and RST. Conjugation of the drugs sustained in vitro release; thus, their leakage when injected into the blood stream was prevented to avoid systemic side effects. The hydrophobic drug HK was incorporated via physical loading within the hydrophobic core of $\mathrm{NHs}$, improving its release pattern. Crosslinking of $\mathrm{NHs}$ with genipin was developed to improve the stability of the NH structure, sustain drug release and avoid premature disintegration. Crosslinked HK/PMT-ALG/LF-RST NHs F10 showed a narrow PDI, appropriate size, elevated negative zeta potential, high percentage drug loading of PMT, RST and HK in addition to good serum stability and hemocompatibility. Furthermore, crosslinked HK/PMT-ALG/LF-RST NHs F10 enhanced cellular uptake into the MCF-7 breast cancer cell line and exhibited superior cytotoxicity. In vivo, crosslinked HK/PMT-ALG/LF-RST NHs F10 reduced the tumor size by inhibiting the expression levels of ki-67 and VEGF-1, which could suppress tumor proliferation. Furthermore, the expression level of active caspase-3 was upregulated, where induction of apoptosis in the tumor tissue of EATbearing mice was achieved by crosslinked HK/PMT-ALG/LF-RST NHs F10. We can conclude that crosslinked HK/PMT-ALG/LFRST NHs F10 is a promising nanocarrier for targeted cancer treatment.

\section{Abbreviations}

RST: Rosuvastatin; PMT: Pemetrexed; HK: Honokiol; ALG: Alginate; LF: lactoferrin; NHs: nanohybrids; NPs: Nanoparticles; MDR: Multi-drug resistance; HMG-CO A: $\beta$-hydroxy $\beta$-methylglutaryl-CoA reductase; MVA: Mevalonate pathway; SREBP2: sterol regulatory element-binding protein 2; LDL: low-density lipoprotein; DMSO: dimethyl sulfoxide; RT: Room temperature; TEM: Transmission electron microscopy; SI: Supporting information; CST: Celastrol; $\mathrm{D}_{2} \mathrm{O}$ : deuterium oxide; DTX: docetaxel; DRI: Dose Reduction Index; Cl: Combination Index; EAT: Ehrlich ascites tumor; VEGF-1: Vascular endothelial growth factor; PDI: Polydispersity index.

\section{Declarations}

\section{Availability of data and materials}

All data used to generate these results are available in the main text and supporting information.

\section{Supplementary Information}

Physicochemical characterization of crosslinked HK-loaded PMT-ALG/LF-RST NHs. In vitro cytotoxicity study and in vitro cellular uptake. In vivo studies.

\section{Ethics declarations}

\section{Ethics approval and consent to participate}

All animal experimental procedures were performed according to a protocol approved by the Animal Care and Use Committee of the Faculty of Pharmacy, Alexandria University, Alexandria, Egypt, and in accordance with regulations of the National Research Council's guide for the care and use of laboratory animals.

\section{Consent for publication}

All authors agree to be published.

\section{Competing interests}

The authors declare that they have no conflicts of interest.

\section{Funding:}


Funding by the Mai Sherif Foundation, Alexandria, Egypt.

Authors' contributions:

MS, MAA: Methodology, Validation. SNK, AOE: Conceptualization, Formal analysis, Supervision, Resources. MT, MAS, AFK, AEN: Visualization, Investigation. MS, MAA: Writing main manuscript text. KAE, AAB: Resources, Supervision. SNK, KAE: Writing Review \& Editing.

Acknowledgement:

The authors thank the Mai Sherif Foundation, Alexandria, Egypt, for partially funding this work.

\section{References}

1. Sabra SA, Elzoghby AO, Sheweita SA, Haroun M, Helmy MW, Eldemellawy MA, Xia Y, Goodale D, Allan AL, Rohani S: Selfassembled amphiphilic zein-lactoferrin micelles for tumor targeted co-delivery of rapamycin and wogonin to breast cancer. European Journal of Pharmaceutics and Biopharmaceutics 2018, 128:156-169.

2. Tao Z, Shi A, Lu C, Song T, Zhang Z, Zhao J: Breast Cancer: Epidemiology and Etiology. Cell Biochem Biophys 2015, 72:333338.

3. Nurgali K, Jagoe RT, Abalo R: Adverse effects of cancer chemotherapy: Anything new to improve tolerance and reduce sequelae? Frontiers in pharmacology 2018, 9:245.

4. Shabbits J, Hu Y, Mayer L: Tumor Chemosensitization Strategies Based on Apoptosis Manipulations1. Molecular cancer therapeutics 2003, 2:805-813.

5. Hu CM, Zhang L: Nanoparticle-based combination therapy toward overcoming drug resistance in cancer. Biochem Pharmacol 2012, 83:1104-1111.

6. Zhou L-Y, Shi Y-H, Jia Y-S, Tong Z-S: Potential role of pemetrexed in metastatic breast cancer patients pre-treated with anthracycline or taxane. Chronic diseases and translational medicine 2015, 1:27-35.

7. Yang W, Yang L, Xia Y, Cheng L, Zhang J, Meng F, Yuan J, Zhong Z: Lung cancer specific and reduction-responsive chimaeric polymersomes for highly efficient loading of pemetrexed and targeted suppression of lung tumor in vivo. Acta Biomaterialia 2018, 70:177-185.

8. Duan W, Liu Y: Targeted and synergistic therapy for hepatocellular carcinoma: monosaccharide modified lipid nanoparticles for the co-delivery of doxorubicin and sorafenib. Drug Design, Development and Therapy 2018, 12:2149.

9. Cao H, Wang Y, He X, Zhang Z, Yin Q, Chen Y, Yu H, Huang Y, Chen L, Xu M: Codelivery of sorafenib and curcumin by directed self-assembled nanoparticles enhances therapeutic effect on hepatocellular carcinoma. Molecular pharmaceutics 2015, 12:922-931.

10. Cova E, Pandolfi L, Colombo M, Frangipane V, Inghilleri S, Morosini M, Mrakic-Sposta S, Moretti S, Monti M, Pignochino Y, et al: Pemetrexed-loaded nanoparticles targeted to malignant pleural mesothelioma cells: an in vitro study. International journal of nanomedicine 2019, 14:773-785.

11. Gabr MM, Mortada SM, Sallam MA: Carboxylate cross-linked cyclodextrin: A nanoporous scaffold for enhancement of rosuvastatin oral bioavailability. Eur J Pharm Sci 2018, 111:1-12.

12. Gabr MM, Mortada SM, Sallam MA: Hexagonal Liquid Crystalline Nanodispersions Proven Superiority for Enhanced Oral Delivery of Rosuvastatin: In Vitro Characterization and In Vivo Pharmacokinetic Study. J Pharm Sci 2017, 106:3103-3112.

13. El Sayed I, Helmy MW, El-Abhar HS: Inhibition of SRC/FAK cue: A novel pathway for the synergistic effect of rosuvastatin on the anti-cancer effect of dasatinib in hepatocellular carcinoma. Life Sciences 2018, 213:248-257.

14. van Leeuwen J, Ba-Alawi W, Branchard E, Longo J, Silvester J, Cescon DW, Haibe-Kains B, Penn LZ, Gendoo DMA: Computational pharmacogenomics screen identifies synergistic statin-compound combinations as anti-breast cancer therapies. bioRxiv 2020:2020.2009.2007.286922. 
15. Holstein SA, Hohl RJ: Synergistic interaction of lovastatin and paclitaxel in human cancer cells. Molecular cancer therapeutics 2001, 1 2:141-149.

16. Arora S, Singh S, Piazza GA, Contreras CM, Panyam J, Singh AP: Honokiol: a novel natural agent for cancer prevention and therapy. Curr Mol Med 2012, 12:1244-1252.

17. Khafaga AF, Shamma RN, Abdeen A, Barakat AM, Noreldin AE, Elzoghby AO, Sallam MA: Celecoxib repurposing in cancer therapy: molecular mechanisms and nanomedicine-based delivery technologies. Nanomedicine (Lond) 2021, 16:1691-1712.

18. Helal HM, Samy WM, El-Fakharany EM, Kamoun EA, Mortada SM, Sallam MA: Maltodextrin-a-tocopherol conjugates of vitamin E: Influence of degree of derivatization on physicochemical properties and biological evaluation. Journal of Drug Delivery Science and Technology 2020, 60:102097.

19. Sallam MA, Wyatt Shields Iv C, Prakash S, Kim J, Pan DC, Mitragotri S: A dual macrophage polarizer conjugate for synergistic melanoma therapy. J Control Release 2021, 335:333-344.

20. Sallam MA, Prakash S, Krishnan V, Todorova K, Mandinova A, Mitragotri S: Hyaluronic Acid Conjugates of Vorinostat and Bexarotene for Treatment of Cutaneous Malignancies. Advanced Therapeutics 2020, 3:2000116.

21. Dolz-Pérez I, Sallam MA, Masiá E, Morelló-Bolumar D, Del Caz MDP, Graff P, Abdelmonsif D, Hedtrich S, Nebot VJ, Vicent MJ: Polypeptide-corticosteroid conjugates as a topical treatment approach to psoriasis. Journal of Controlled Release 2020, 318:210-222.

22. Qi J, Yao P, He F, Yu C, Huang C: Nanoparticles with dextran/chitosan shell and BSA/chitosan core-Doxorubicin loading and delivery. International Journal of Pharmaceutics 2010, 393:177-185.

23. Peng P, Yang K, Tong G, Ma L: Polysaccharide Nanoparticles for Targeted Cancer Therapies. Curr Drug Metab 2018, 19:781792.

24. Abdelmoneem M, Abd Elwakil M, Khattab ShN, Helmy M, Bekhit A, Abdulkader M, Zaky A, Elkhodairy K, Albericio F, Elzoghby A: Lactoferrin-Dual Drug Nanoconjugate: Synergistic Anti-Tumor Efficacy of Docetaxel and the NF-kB inhibitor Celastrol. Materials Science and Engineering C 2021:111422.

25. Cherkupally P, Acosta GA, Nieto-Rodriguez L, Spengler J, Rodriguez H, Khattab ShN, El-Faham A, Shamis M, Luxembourg Y, Prohens R, et al: K-Oxyma: a Strong Acylation-Promoting, 2-CTC Resin-Friendly Coupling Additive. European Journal of Organic Chemistry 2013, 2013:6372-6378.

26. Siegel RL, Miller KD, Jemal A: Cancer statistics, 2020. CA: A Cancer Journal for Clinicians 2020, 70:7-30.

27. Mitachi K, Kurosu YE, Hazlett BT, Kurosu M: Oxyma-based phosphates for racemization-free peptide segment couplings. Journal of peptide science : an official publication of the European Peptide Society 2016, 22:186-191.

28. El-Faham A, Khattab ShN, Abdul-Ghani M, Albericio F: Design and Synthesis of New Immonium-Type Coupling Reagents. European Journal of Organic Chemistry 2006, 2006:1563-1573.

29. Khattab ShN: Ethyl 2-Cyano-2-(hydroxyimino)acetate (Oxyma): An Efficient and Convenient Additive Used with Tetramethylfluoroformamidinium Hexafluorophosphate (TFFH) to Replace 1-Hydroxybenzotriazole (HOBt) and 1-Hydroxy-7azabenzotriazole (HOAt) during Peptide Synthesis. Bulletin of the Chemical Society of Japan 2010, 83:1374-1379.

30. Khattab ShN: Sulfonate Esters of 1-Hydroxypyridin-2(1H)-one and Ethyl 2-Cyano-2-(hydroxyimino)acetate (Oxyma) as Effective Peptide Coupling Reagents to Replace 1-Hydroxybenzotriazole and 1-Hydroxy-7-azabenzotriazole. Chemical \& pharmaceutical bulletin 2010, 58:501-506.

31. Jad YE, Khattab ShN, de la Torre BG, Govender T, Kruger HG, El-Faham A, Albericio F: EDC.HCl and Potassium Salts of Oxyma and Oxyma-B as Superior Coupling Cocktails for Peptide Synthesis. European Journal of Organic Chemistry 2015, 2015:3116-3120.

32. Zhou C, Gao W, Lu G, Ding J, Wu X, Huang X, Chen J, Liu M, Jiang J, Wu H: Preparation, characterization and in vitro release of microparticles based on dextran-rosuvastatin conjugate. Carbohydrate Polymers 2013, 96:156-162.

33. Dey S, Sreenivasan K: Conjugation of curcumin onto alginate enhances aqueous solubility and stability of curcumin. Carbohydrate Polymers 2014, 99:499-507.

34. Martínez A, Iglesias I, Lozano R, Teijón JM, Blanco MD: Synthesis and characterization of thiolated alginate-albumin nanoparticles stabilized by disulfide bonds. Evaluation as drug delivery systems. Carbohydrate Polymers 2011, 83:1311- 
1321.

35. Anwar D, Khattab ShN, Helmy M, Kamal M, Bekhit A, Elkhodairy K, Elzoghby A: Lactobionic/Folate Dual-Targeted Amphiphilic Maltodextrin-Based Micelles for Targeted Codelivery of Sulfasalazine and Resveratrol to Hepatocellular Carcinoma. Bioconjugate Chemistry 2018, 29.

36. Helal HM, Samy WM, Kamoun EA, El-Fakharany EM, Abdelmonsif DA, Aly RG, Mortada SM, Sallam MA: Potential Privilege of Maltodextrin-a-Tocopherol Nano-Micelles in Seizing Tacrolimus Renal Toxicity, Managing Rheumatoid Arthritis and Accelerating Bone Regeneration. International Journal of Nanomedicine 2021, 16:4781.

37. Sabra S, Elzoghby A, Sheweita S, Haroun M, Helmy M, Eldemellawy M, Xia Y, Allan A, Rohani S: Self-assembled amphiphilic zein-lactoferrin micelles for tumor targeted co-delivery of rapamycin and wogonin to breast cancer. European Journal of Pharmaceutics and Biopharmaceutics 2018, 128.

38. Kapure VJ, Pande VV, Deshmukh PK: Dissolution Enhancement of Rosuvastatin Calcium by Liquisolid Compact Technique. Journal of Pharmaceutics 2013, 2013:315902.

39. Zayed D, Ebrahim S, Helmy M, Khattab ShN, Bahey-El-Din M, Fang J-Y, Elkhodairy K, Elzoghby A: Combining hydrophilic chemotherapy and hydrophobic phytotherapy via tumor-targeted albumin-QDs nano-hybrids: Covalent coupling and phospholipid complexation approaches. Journal of Nanobiotechnology 2019, 17.

40. Metawea O, Abdelmoneem M, Haiba N, Khalil H, Elzoghby A, Khafaga A, Noreldin A, Albericio F, Khattab ShN: A novel 'smart' PNIPAM-based copolymer for breast cancer targeted therapy: Synthesis, and characterization of dual pH/temperatureresponsive lactoferrin-targeted PNIPAM-co-AA. Colloids and Surfaces B: Biointerfaces 2021, 202:111694.

41. O'Riordan N, Kane M, Joshi L, Hickey RM: Structural and functional characteristics of bovine milk protein glycosylation. Glycobiology 2014, 24:220-236.

42. Elgindy N, Elkhodairy K, Molokhia A, Elzoghby A: Lyophilization monophase solution technique for preparation of amorphous flutamide dispersions. Drug development and industrial pharmacy 2011, 37:754-764.

43. Date PV, Samad A, Devarajan PV: Freeze Thaw: A Simple Approach for Prediction of Optimal Cryoprotectant for Freeze Drying. AAPS PharmSciTech 2010, 11:304-313.

44. Müller-Goymann CC: Physicochemical characterization of colloidal drug delivery systems such as reverse micelles, vesicles, liquid crystals and nanoparticles for topical administration. European Journal of Pharmaceutics and

Biopharmaceutics 2004, 58:343-356.

45. Nahar M, Mishra D, Dubey V, Jain NK: Development, characterization, and toxicity evaluation of amphotericin B-loaded gelatin nanoparticles. Nanomedicine: Nanotechnology, Biology and Medicine 2008, 4:252-261.

46. Karymov MA, Procházka K, Mendenhall JM, Martin TJ, Munk P, Webber SE: Chemical Attachment of Polystyrene-blockpoly(methacrylic acid) Micelles on a Silicon Nitride Surface. Langmuir 1996, 12:4748-4753.

47. Martinez AW, Caves JM, Ravi S, Li W, Chaikof EL: Effects of crosslinking on the mechanical properties, drug release and cytocompatibility of protein polymers. Acta biomaterialia 2014, 10:26-33.

48. Liu Z, Wang Y, Zhang J, Li M, Liu Y, Zhang N: Pluronic P123-Docetaxel Conjugate Micelles: Synthesis, Characterization, and Antitumor Activity. Journal of Biomedical Nanotechnology 2013, 9:2007-2016.

49. Markovsky E, Baabur-Cohen H, Satchi-Fainaro R: Anticancer polymeric nanomedicine bearing synergistic drug combination is superior to a mixture of individually-conjugated drugs. Journal of Controlled Release 2014, 187:145-157.

50. Xu Q, Yuan X, Chang J: Self-aggregates of cholic acid hydrazide-dextran conjugates as drug carriers. Journal of Applied Polymer Science 2005, 95:487-493.

51. Kwon GS, Forrest ML: Amphiphilic block copolymer micelles for nanoscale drug delivery. Drug Development Research 2006, 67:15-22.

52. Göppert TM, Müller RH: Adsorption kinetics of plasma proteins on solid lipid nanoparticles for drug targeting. International journal of pharmaceutics 2005, 302:172-186.

53. Yang S, Zhang B, Gong X, Wang T, Liu Y, Zhang N: In vivo biodistribution, biocompatibility, and efficacy of sorafenib-loaded lipid-based nanosuspensions evaluated experimentally in cancer. International journal of nanomedicine 2016, 11:2329. 
54. Brash JL: Chapter 2 - Blood compatibility of nanomaterials. In Drug Delivery Nanosystems for Biomedical Applications. Edited by Sharma CP: Elsevier; 2018: 13-31

55. Chou T-C: Drug combinations: from laboratory to practice. The Journal of laboratory and clinical medicine 1998, 132:6-8.

56. Chou T, Talalay P: Applications of the median-effect principle for the assessment of low-dose risk of carcinogens and for the quantitation of synergism and antagonism of chemotherapeutic agents. New avenues in developmental cancer chemotherapy 1987, 8:37-64.

57. Chou T-C, Talaly P: A simple generalized equation for the analysis of multiple inhibitions of Michaelis-Menten kinetic systems. Journal of Biological Chemistry 1977, 252:6438-6442.

58. Salatin S, Yari Khosroushahi A: Overviews on the cellular uptake mechanism of polysaccharide colloidal nanoparticles. $J$ Cell Mol Med 2017, 21:1668-1686.

59. Ahire JH, Chambrier I, Mueller A, Bao Y, Chao Y: Synthesis of d-Mannose Capped Silicon Nanoparticles and Their Interactions with MCF-7 Human Breast Cancerous Cells. ACS Applied Materials \& Interfaces 2013, 5:7384-7391.

60. Maharjan R, Pangeni R, Jha SK, Choi JU, Chang K-Y, Choi YK, Park JW, Byun Y: Anti-Angiogenic Effect of Orally Available Pemetrexed for Metronomic Chemotherapy. Pharmaceutics 2019, 11.

61. Semenova AE, Sergienko IV, Masenko VP, Ezhov MV, Gabrusenko SA, Kuharchuk VV, Belenkov YN: The influence of rosuvastatin therapy and percutaneous coronary intervention on angiogenic growth factors in coronary artery disease patients. Acta Cardiol 2009, 64:405-409.

62. Haggag YA, Ibrahim RR, Hafiz AA: Design, Formulation and in vivo Evaluation of Novel Honokiol-Loaded PEGylated PLGA Nanocapsules for Treatment of Breast Cancer. Int J Nanomedicine 2020, 15:1625-1642.

63. Nagalingam A, Arbiser JL, Bonner MY, Saxena NK, Sharma D: Honokiol activates AMP-activated protein kinase in breast cancer cells via an LKB1-dependent pathway and inhibits breast carcinogenesis. Breast Cancer Res 2012, 14:R35.

64. Liu H, Zang C, Emde A, Planas-Silva MD, Rosche M, Kühnl A, Schulz C-O, Elstner E, Possinger K, Eucker J: Anti-tumor effect of honokiol alone and in combination with other anti-cancer agents in breast cancer. European journal of pharmacology 2008, 591:43-51.

65. Chen K-C, Yang T-Y, Wu C-C, Cheng C-C, Hsu S-L, Hung H-W, Chen J-W, Chang G-C: Pemetrexed Induces S-Phase Arrest and Apoptosis via a Deregulated Activation of Akt Signaling Pathway. PLOS ONE 2014, 9:e97888.

66. Tian W, Xu D, Deng Y-C: Honokiol, a multifunctional tumor cell death inducer. Die Pharmazie-An International Journal of Pharmaceutical Sciences 2012, 67:811-816.

67. Li X, Song H, Kong F, Guo Y, Chen Y, Zhang L, Gao D, Zhao X, Zhang H: Pemetrexed exerts anticancer effects by inducing G(0)/G(1)-phase cell cycle arrest and activating the NOXA/Mcl-1 axis in human esophageal squamous cell carcinoma cells. Oncology letters 2019, 17:1851-1858.

68. Cui J, Zhang Y, Su D, Li T, Li Y: Efficacy of combined icotinib and pemetrexed in EGFR mutant lung adenocarcinoma cell line xenografts. Thoracic Cancer 2018, 9:1156-1165.

69. Bjarnadottir O, Romero Q, Bendahl PO, Jirström K, Rydén L, Loman N, Uhlén M, Johannesson H, Rose C, Grabau D, Borgquist S: Targeting HMG-CoA reductase with statins in a window-of-opportunity breast cancer trial. Breast Cancer Res Treat 2013, 138:499-508.

\section{Figures}




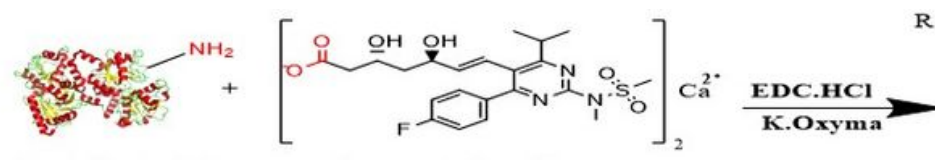

Lactoferrin (Lf)

Rosuvastatin calcium

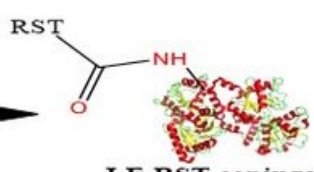

LF-RST conjugate

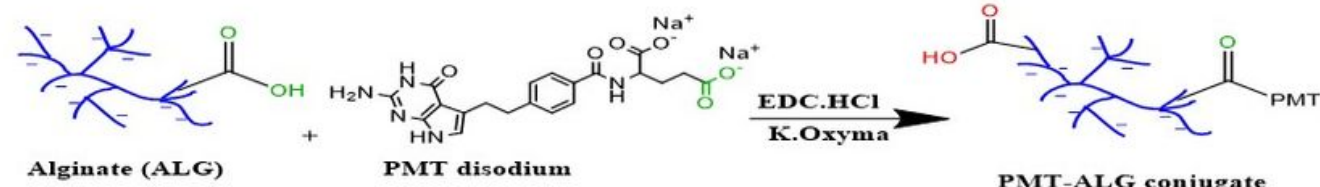

Alginate (ALG)

PMT disodium

PMT-ALG conjugate
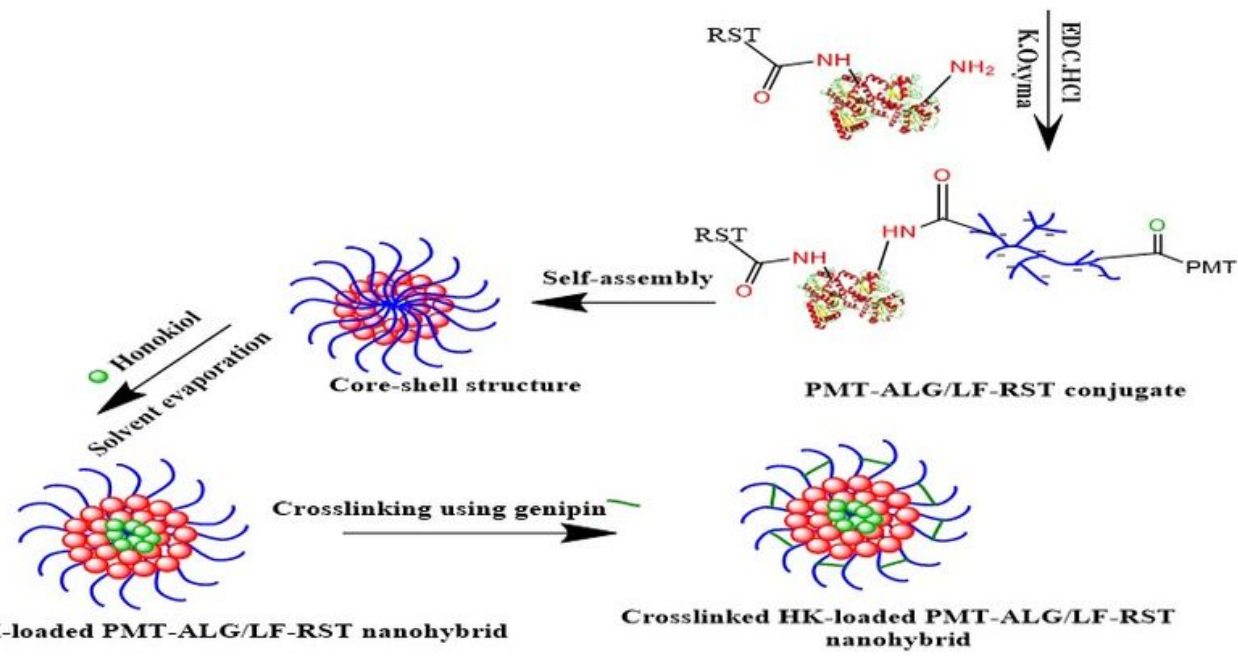

HK-loaded PMT-ALG/LF-RST nanohybrid nanohybrid

\section{Figure 1}

Schematic diagram showing the formulation stages of crosslinked HK-loaded PMT-ALG/LF-RST NH. 

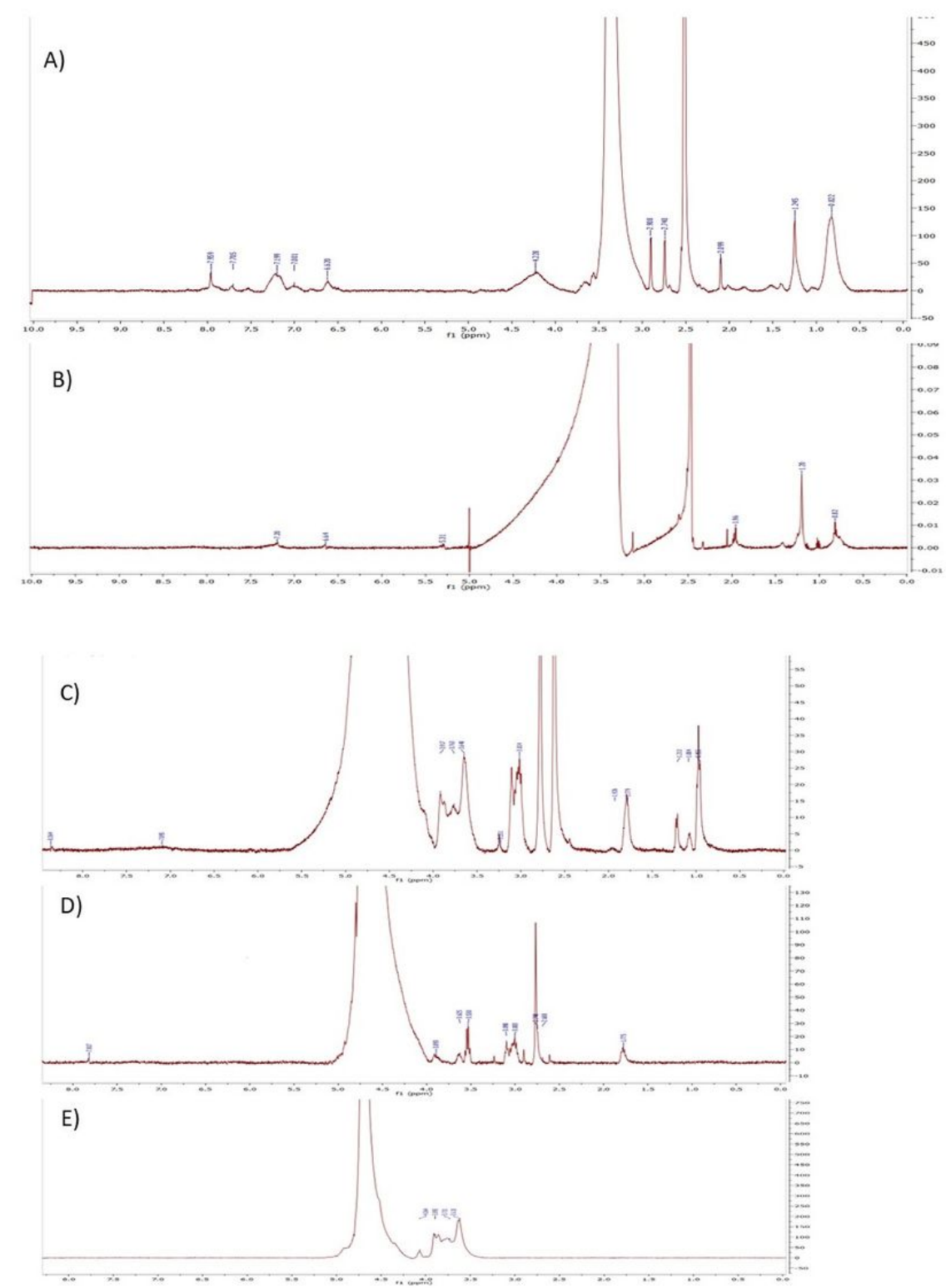

Figure 2

${ }^{1} \mathrm{H}$ NMR (DMSO- $\left.d_{6}\right)$ spectra of (A): LF-RST, (B): LF and ${ }^{1} \mathrm{H}$ NMR $\left(\mathrm{D}_{2} \mathrm{O}\right)$ spectra of (c): PMT-ALG/LF-RST NHs, (D): PMT-ALG and (E): ALG 

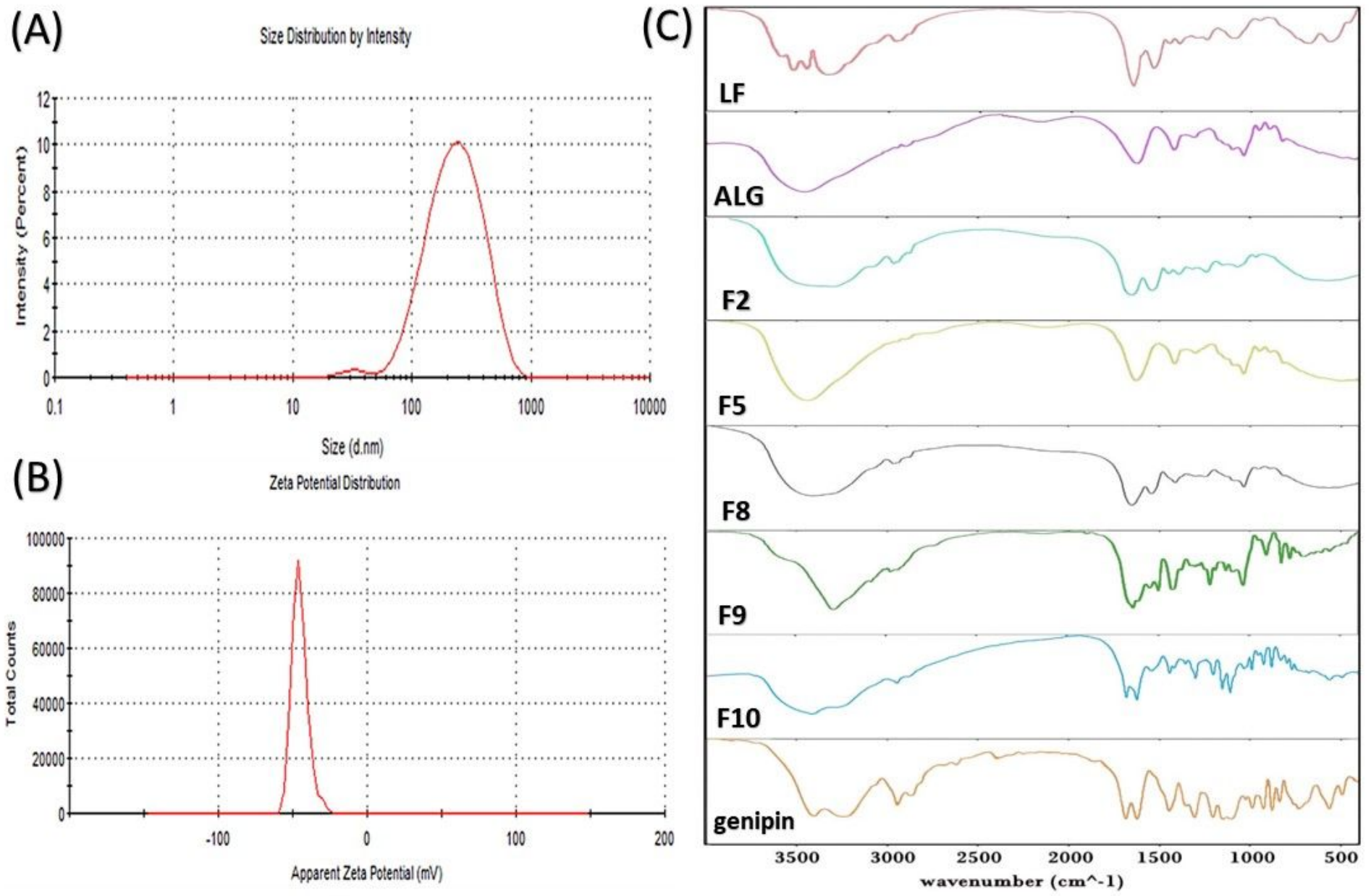

Figure 3

(A) Size distribution diagram of crosslinked HK-loaded PMT-ALG/LF-RST NHs F10; (B) $\zeta$ potential of NHs F10 and (C) Fourier transform infrared (FTIR) spectra of LF, ALG, LF-RST F2, PMT-ALG F5, PMT-ALG/LF-RST F8, HK-loaded PMT-ALG/LF-RST F9, genipin and crosslinked HK-loaded PMT-ALG/LF-RST NHs F10 

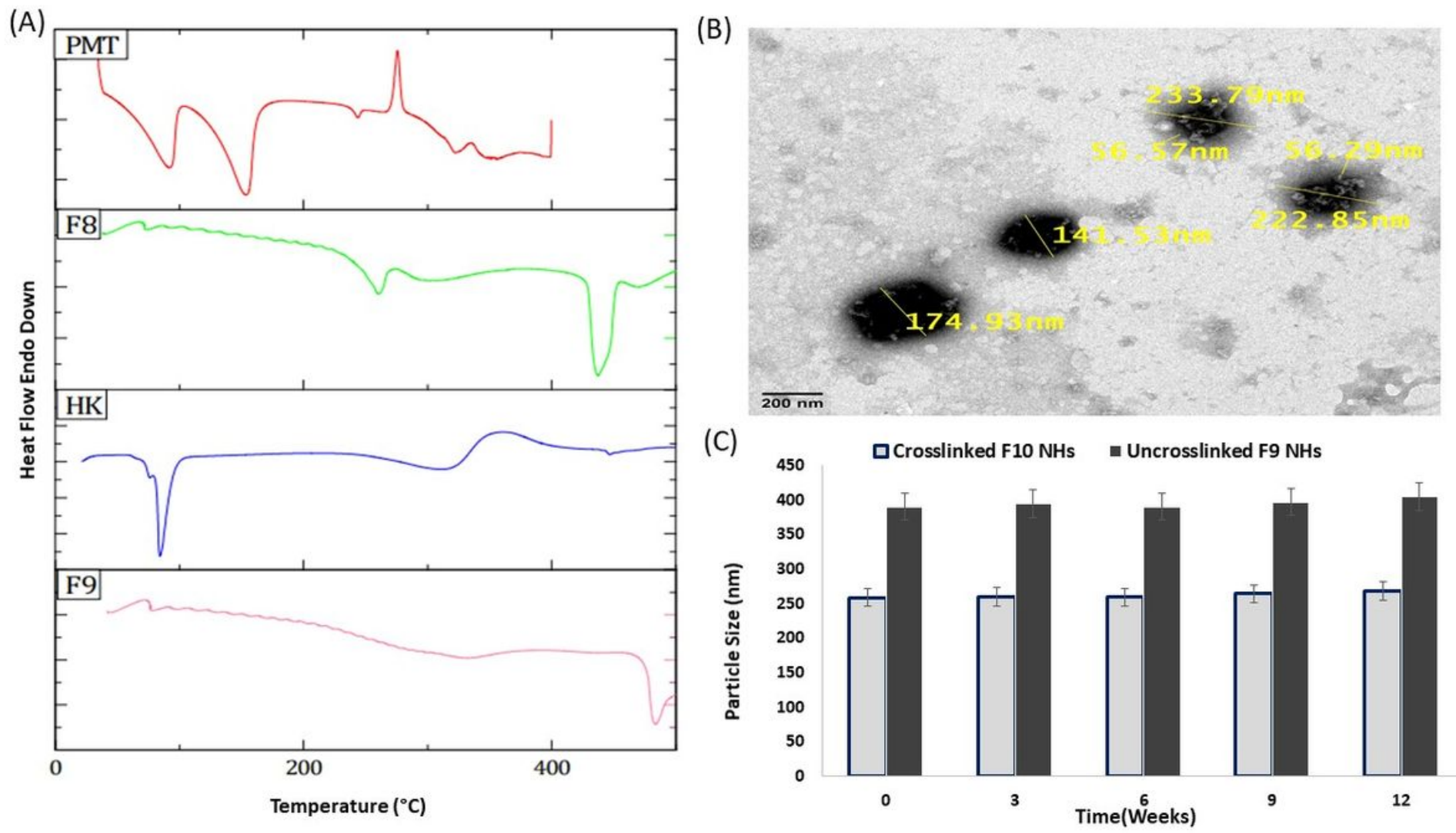

Figure 4

(A) DSC thermograms of PMT, HK, PMT-ALG/LF-RST F8 and HK-loaded PMT-ALG/LF-RST F9; (B) TEM image of crosslinked HKloaded PMT-ALG/LF-RST NHs F10; (C) physical stability of uncrosslinked F9 and crosslinked NHs F10 revealing particle size change with time $(n=3)$.

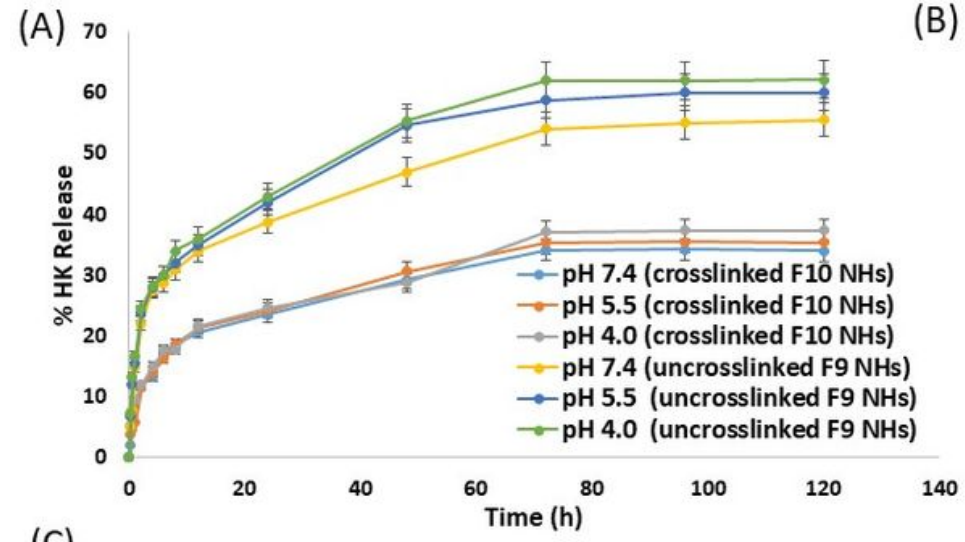

(C)

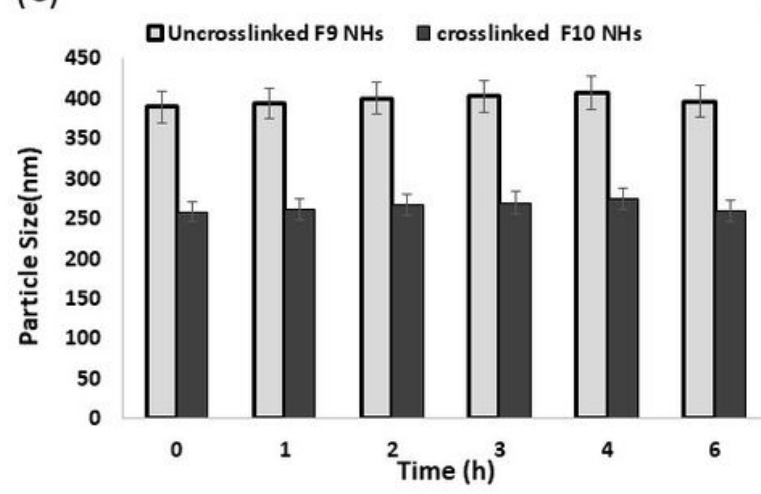

(B)

(D) 4.5
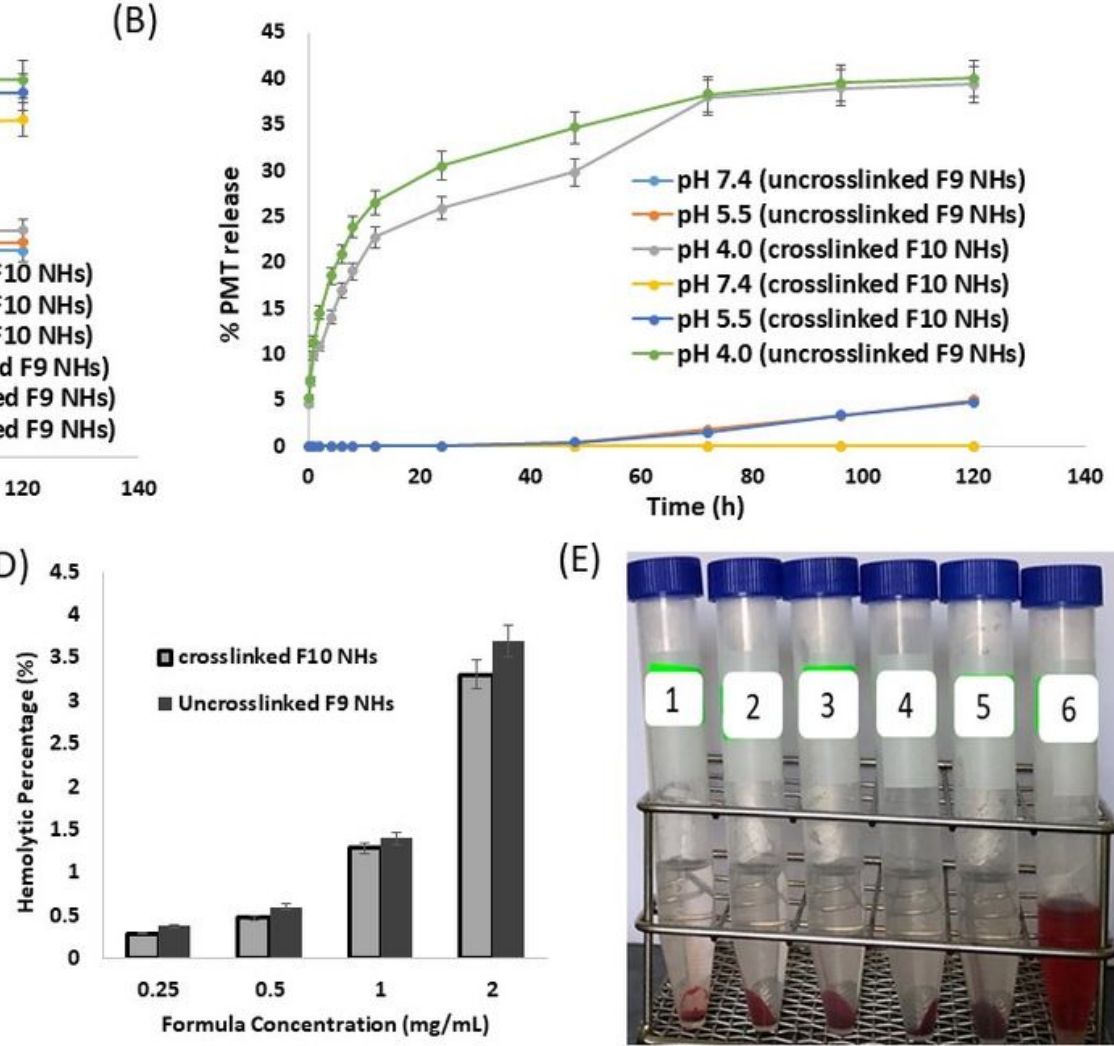

(E)

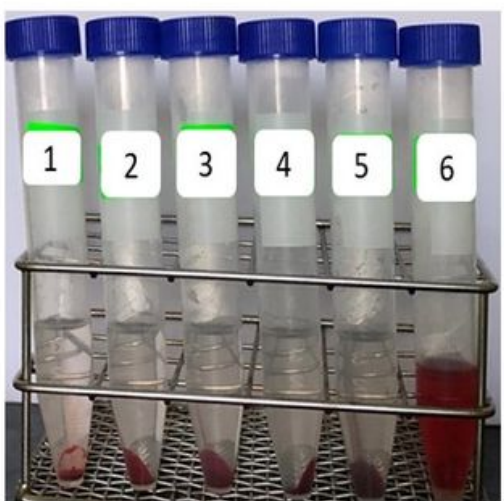


Figure 5

(A): In vitro drug release of HK from uncrosslinked F9 and crosslinked F10 NHs; (B): PMT from F9 and F10 NHs (n=3); (C) serum stability of F9 and F10 NHs (n=3); (D) hemolytic effect of F9 and F10 NHs (n=3); and (E) image of hemocompatibility at $37^{\circ} \mathrm{C}$ with RBCs after $1 \mathrm{~h}$ of incubation.

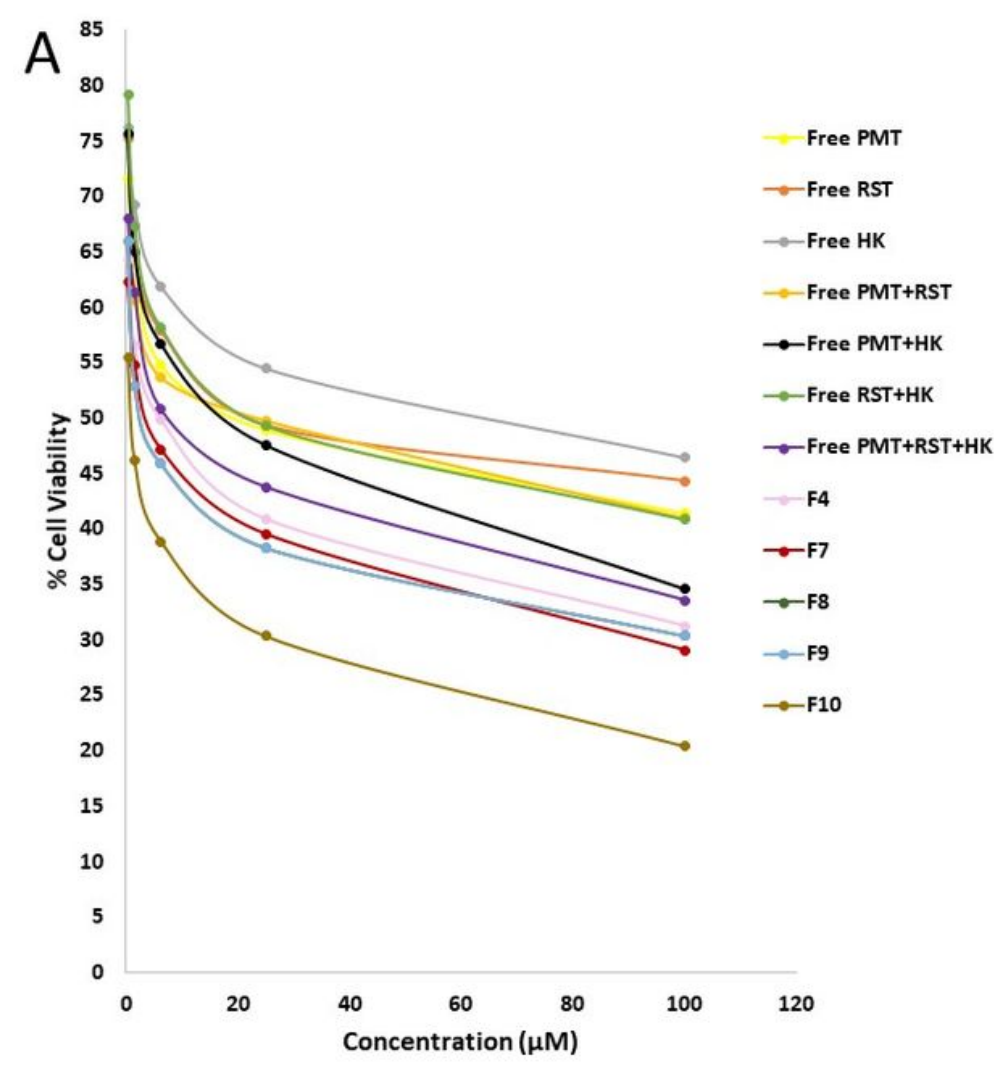

B 70

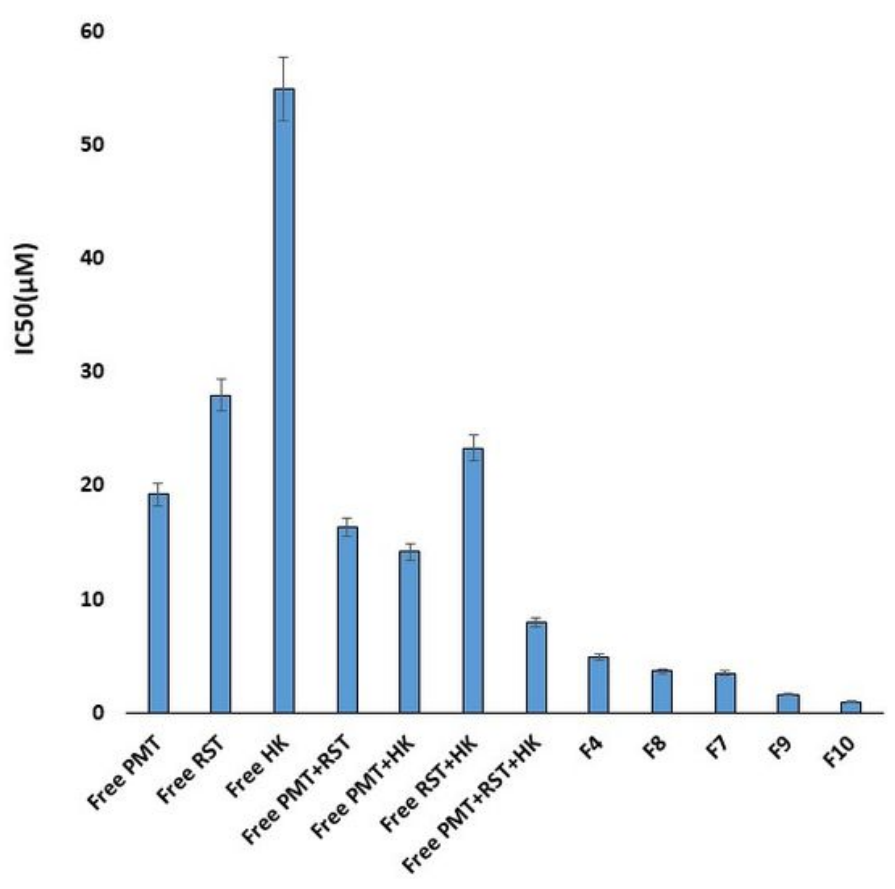

Figure 6

(A): Cytotoxicity of free HK, free RST, free PMT, free PMT/RST combination, free PMT/HK combination, free HK/RST combination, free RST/PMT/HK combination, HK-loaded ALG/LF-RST NHs F4, HK-loaded PMT-ALG/LF NHs F7, PMT-ALG/LFRST NHs F8, uncrosslinked F9 NHs, and crosslinked F10 NHs on MCF-7 breast cancer cell line. (B) IC ${ }_{50}$ of free drugs and different nanoformulations $(n=3)$. 
(A)
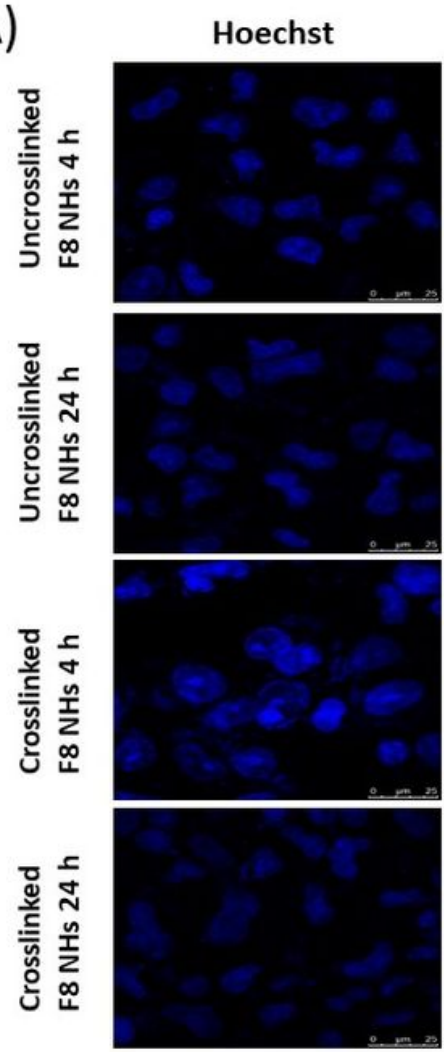

RBITC
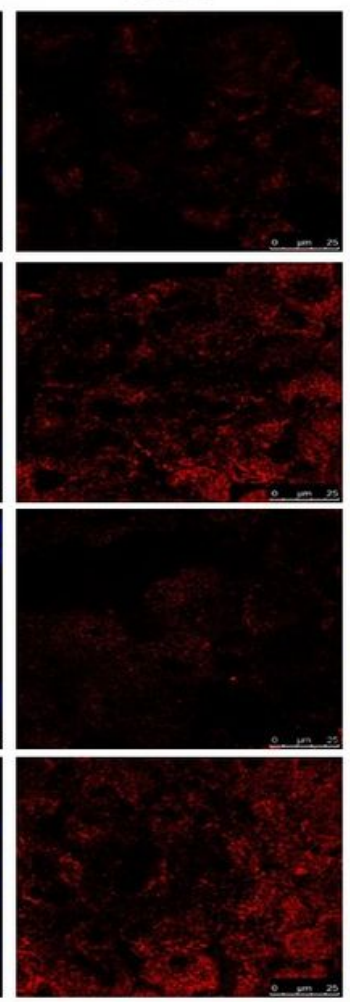

Merged
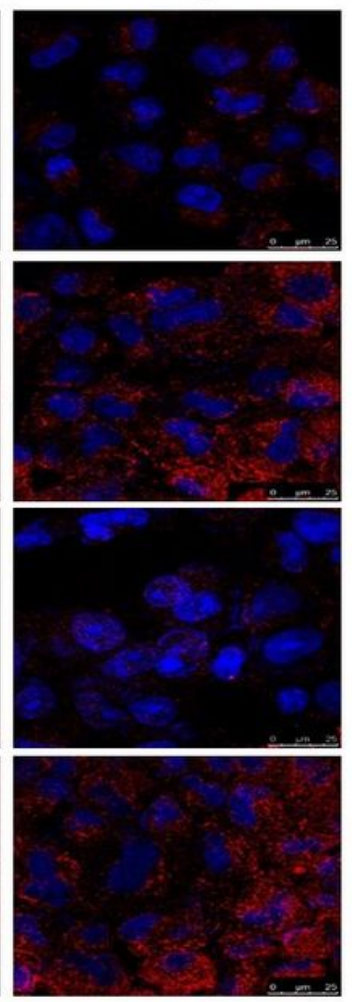

(B)
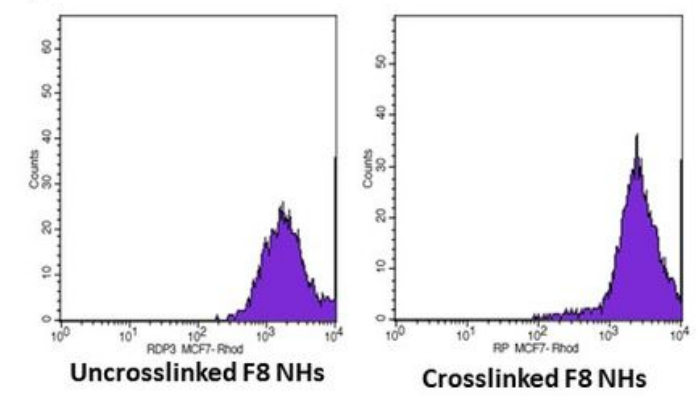

(C)

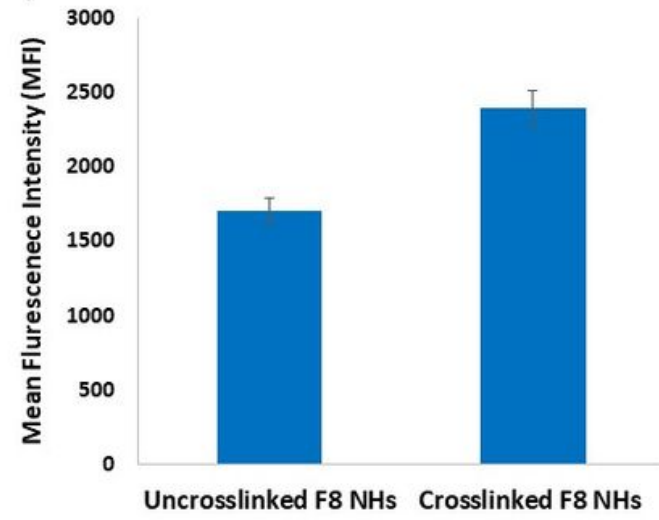

Figure 7

(A) Confocal images revealing the uptake of uncrosslinked and crosslinked PMT-ALG/LF-RST NHs F8 after incubation for $4 \mathrm{~h}$ and $24 \mathrm{~h}$; (B) histogram profiles of flow cytometry of MCF-7 cells after incubation for $4 \mathrm{~h}$; (C) estimation of the mean fluorescence intensity level in MCF-7 cells after incubation for $4 \mathrm{~h}$ with RBITC-labeled uncrosslinked and crosslinked PMTALG/LF-RST NHs F8 ( $n=3)$. 


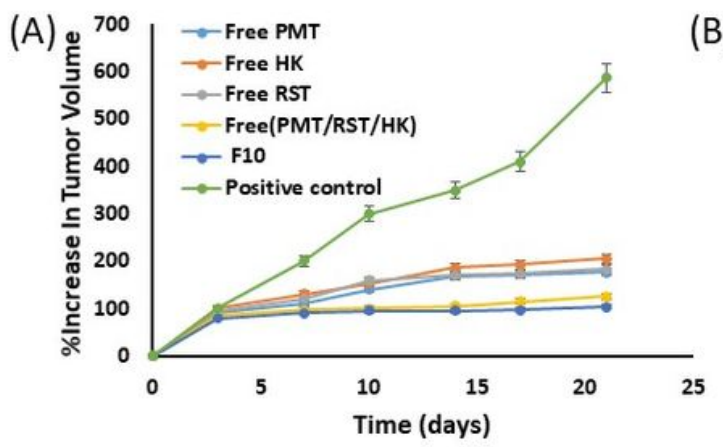

(D)

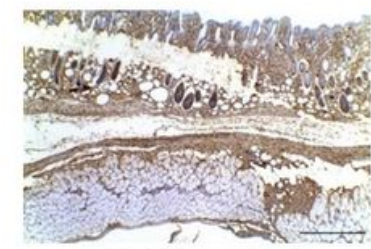

Positive control

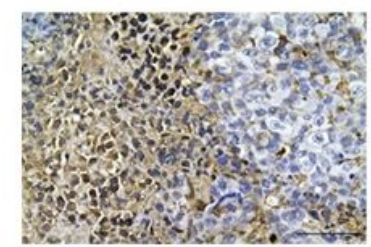

Free PMT
(B)
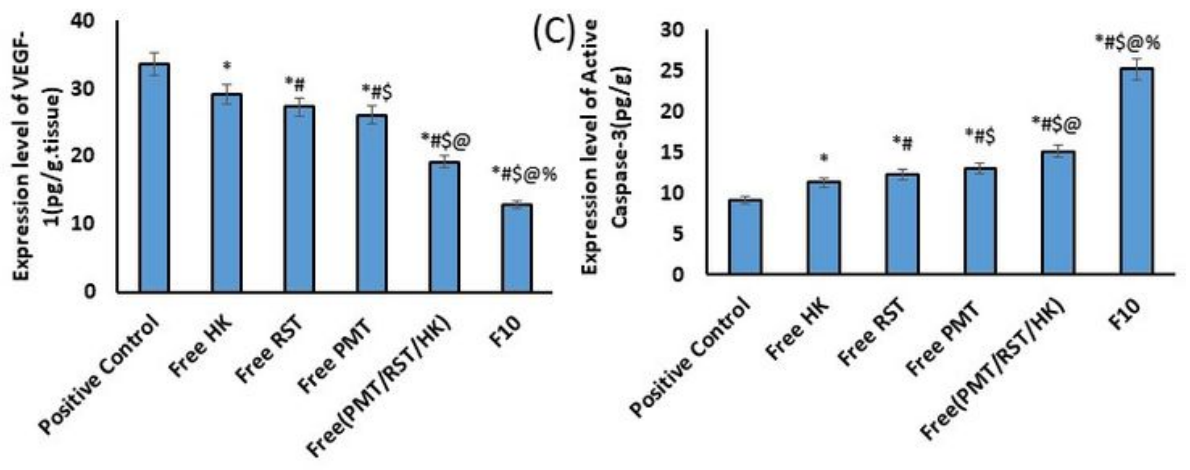

(E)

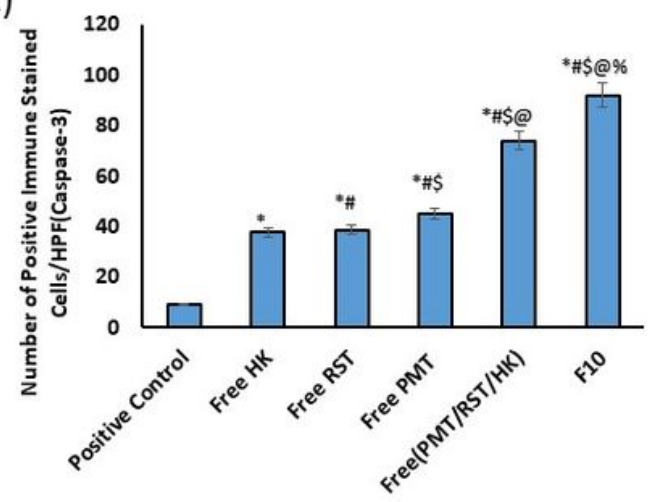

Figure 8

(A) Percentage of elevation in tumor volume of mice bearing EAT detected at pre-established intervals. Quantitative expression of

(B) VEGF-1, (C) level of active caspase-3 for the investigated groups by ELISA. (D) Immunohistochemical staining of Active caspase-3, and (E) The level of \% Active caspase-3 in positive control group and EAT tissues of groups treated with the free PMT, free RST, free HK, free (HK/RST/PMT) combination therapy and crosslinked HK-loaded PMT-ALG/LF-RST NHs F10 $(n=4)(* P<$ 0.05 vs. positive control, \# P $<0.05$ vs. free HK, \$ P $<0.05$ vs. Free RST, @ P< 0.05 vs. free PMT, \% P $<0.05$ vs. free (PMT/RST/HK)). 

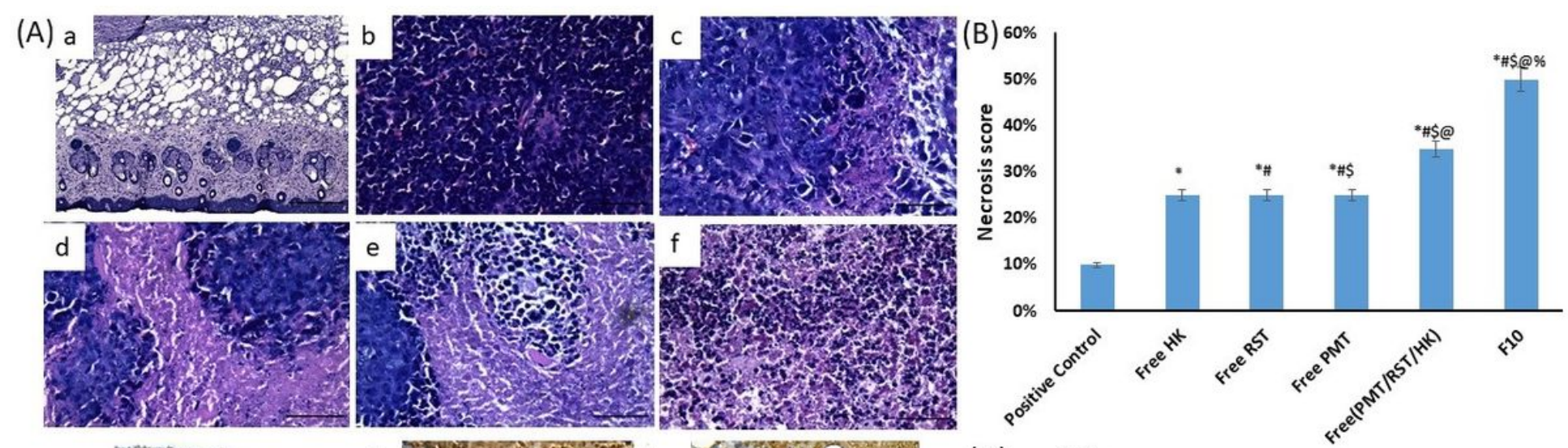

(C)
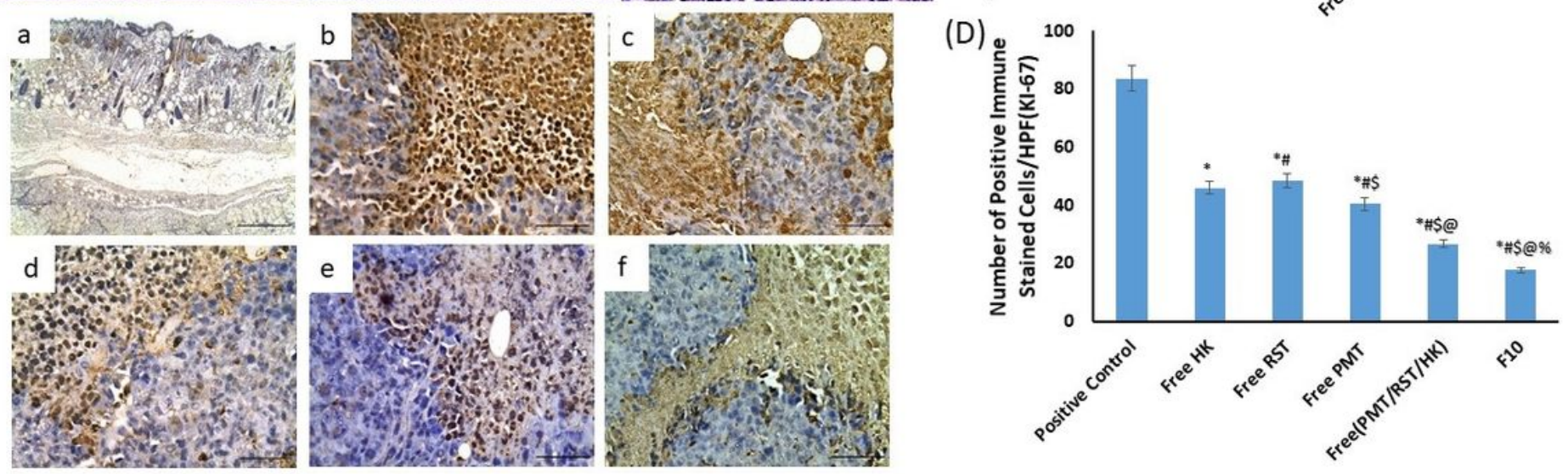

Figure 9

(A) Staining of $\mathrm{H}$ and $\mathrm{E}$ of EAT tissues of (a) positive control group, (b) free HK, (c) free RST, (d) free PMT, (e) free (HK/RST/PMT) combination therapy and (f) crosslinked HK-loaded PMT-ALG/LF-RST NHs F10 treated groups. (B) The necrosis score of H\&Estained sections showed free HK-treated (approximately 25\%), free RST-treated (approximately 25\%), free PMT-treated (approximately 25\%), free PMT/HK/RST combination (approximately 35\%), and crosslinked HK-loaded PMT-ALG/LF-RST NHs F10 ( $\geq 50 \%$ ) mice compared with untreated control positive mice (approximately 10\%). (C) Immunohistopathological staining of Ki-67 in EAT tissues. (D) \% Ki-67 in (a) positive control group and EAT tissues of (b) free HK, (c) free RST, (d) free PMT, (e) free (HK/RST/PMT) combination therapy and (f) crosslinked HK-loaded PMT-ALG/LF-RST NHs F10 treated groups $(n=4)(* P<0.05$ vs. positive control, \# P< 0.05 vs. free HK, $\$ \mathrm{P}<0.05$ vs. Free RST, @ P< 0.05 vs. free PMT, \% $\mathrm{P}<0.05$ vs. free (PMT/RST/HK)).

\section{Supplementary Files}

This is a list of supplementary files associated with this preprint. Click to download.

- JNanobiotechSupportingInformation.docx 